\title{
A VARIABLE-RESOLUTION STRETCHED-GRID GENERAL CIRCULATION MODEL AND DATA ASSIMILATION SYSTEM WITH MULTIPLE AREAS OF INTEREST: STUDYING THE ANOMALOUS REGIONAL CLIMATE
} EVENTS OF 1998

Michael S. Fox-Rabinovitz, ESSIC (Earth System Sciences Interdisciplinary Center), University of Maryland, College Park, MD and Data Assimilation Office, NASA/Goddard Space Flight Center, Greenbelt, MD

Lawrence L. Takacs, and Ravi C. Govindaraju, SAIC (Science Applications International Corporation), 4600 Powder Mill Road, Beltsville, MD 20705-2675, and Data Assimilation Office, NASA/Goddard Space Flight Center, Greenbelt, MD

Corresponding author address: Dr. Michael S. Fox-Rabinovitz, ESSIC, Room 2207, 224 CSS Bldg., University of Maryland, College Park, MD 20742

E-mail: foxrabaatmos.umd.edu or foxrabidao.gsfc.nasa.gov 


\begin{abstract}
The new stretched-grid design with multiple (four) areas of interest, one at each global quadrant, is implemented into both a stretched-grid GCM and a stretched-grid data assimilation system (DAS). The four areas of interest include: the U.S./Northern Mexico, the El-Nino area/Central South America, India/China, and the Eastern Indian Ocean/Australia. Both the stretched-grid GCM and DAS annual (November 1997 through December 1998) integrations are performed with $50 \mathrm{~km}$ regional resolution. The efficient regional down-scaling to mesoscales is obtained for each of the four areas of interest while the consistent interactions between regional and global scales and the high quality of global circulation, are preserved. This is the advantage of the stretchedgrid approach. The global variable-resolution DAS incorporating the stretched-grid GCM has been developed and tested as an efficient tool for producing regional analyses and diagnostics with enhanced mesoscale resolution. The anomalous regional climate events of 1998 that occurred over the U.S., Mexico, South America, China, India, African Sahel, and Australia are investigated in both simulation and data assimilation modes. The assimilated products are also used, along with gauge precipitation data, for validating the simulation results. The obtained results show that the stretched-grid GCM and DAS are capable of producing realistic high quality simulated and assimilated products at mesoscale resolution for regional climate studies and applications.
\end{abstract}




\section{Introduction}

A variable-resolution stretched-grid approach appeared to be an efficient alternative to the nested-grid approach that is widely and successfully used for both short-term regional forecasting and regional climate modeling (e.g. Dickinson et al. 1989, Giorgi 1990, Mesinger 2001, Juang and Kanamitsu 1994). The stretched-grid approach was introduced for grid-point models by Staniforth and Mitchell (1978) and for spectral models by Schmidt (1977). The short-term, 24-48 hour, stretched-grid forecast models (e.g. Staniforth and Daley1979, Courtier and Geleyn 1988) were implemented into the operational practice at the Canadian Meteorological Center since the early 90's (Cote et al. 1993, 1998, Cote 1997, Staniforth 1995, 1997) and since the mid-90's at Meteo-France (e.g. Yessad and Benard 1996). The first regional climate simulation with encouraging results was performed with the Meteo-France model in the mid-90's (Deque and Piedelievre 1995). The model was successfully used for studying the climate change over Europe and for other regional applications (e.g. Deque et al. 1998, Deque 2000).

Other variable-resolution models have been developed for regional applications (e.g. Paegle 1989, Hardiker 1997, McGregor and Katzfey1998).

Development of the Goddard Earth Observing System (GEOS) stretched-grid (SG)GCM for regional applications began in the early-mid 90's. It started from developing the SG-dynamical core without and with orography (Fox-Rabinovitz et al. 1997, 2000). The Held-Suarez framework (Held and Suarez 1994) was employed for experiments. The 
computational noise problems due to grid non-uniformity were resolved (Takacs et al. 1999) and a monotonic noise-free solution was obtained.

The promising results obtained with the SG-dynamical core have justified and prompted applying the SG-approach to a full diabatic GCM. As a result, the full diabatic GEOS SG-GCM has been developed and thoroughly tested, especially in the regional climate simulation mode. The definite efficient regional downscaling to mesoscales is obtained in the experiments with the SG-GCM for the anomalous regional climate events, the 1988 U.S. summer drought and 1993 U.S. summer flood (Fox-Rabinovitz et al. 2001).

An important aspect of that paper was a careful comparison of the SG-GCM and the basic uniform grid GCM simulations (both using the same amount of global grid points). The SG-GCM simulation not only produced realistic mesoscales due to enhanced regional resolution but also was closer to the verifying analyses over the region of interest than that of the basic uniform-grid GCM. The detailed investigation has shown the efficiency of the SG-approach for regional climate modeling.

In the context of participation in the PIRCS (Project to Intercompare Regional Climate Simulations) experiments (e.g. Takle et al. 1999), the SG-GCM was successfully run, in a special simulation mode, for studying the above U.S. summer anomalous climate events (Fox-Rabinovitz 2000). Also, the positive impact from using a finer ( $40 \mathrm{~km}$ versus 60 $\mathrm{km}$ ) regional resolution, was clearly shown in the paper.

These developments made possible, and actually paved the way, for the development of the GEOS SG-DAS (Data Assimilation System) incorporating the GEOS SG-GCM. It is noteworthy that the fine resolution regional analyses and diagnostics produced with the 
GEOS SG-DAS have already been used for validating the SG-GCM regional climate simulations (Fox-Rabinovitz 2000, Fox-Rabinovitz et al. 2001).

Variable-resolution SG-GCM and SG-DAS are the scientifically sound tools for performing cost-effective regional simulation and data assimilation with fine mesoscale resolution over the area(s) of interest. Such fine resolution is not likely to be possible to use in the foreseeable future with fine uniform global grid GCMs and DASs that will be used for climate simulations and for reanalyses. Simply put, any resolution used for existing or future global models/systems can be at least doubled over the area(s) of interest using the SG-approach. Depending on the particular regional resolution used, the computational savings are an order of magnitude compared to the computer time needed for the corresponding GCM or DAS runs with a fine uniform global grid.

The computational efficiency provided by the SG-approach, is not the only reason for its practical implementation. It is at least equally or even more important, in our view, that this approach provides the following desired properties: an efficient regional downscaling; no need for lateral boundary conditions; self-consistent interactions of regional and global scales due to an adequate representation of long waves because of using the global integration domain; and the preservation of a high quality of global circulation. As a result, realistic simulated and assimilated regional fields and diagnostics at fine regional resolution necessary for an adequate representation of mesoscale phenomena, are obtained. It provides an important rationale for developing and using SG-GCMs or SG-DASs for the variety of regional applications. It is noteworthy that an optimal choice between a SG-model/system and a limited-area nested-grid model/system is supposed to be done depending on a specific application framework. 
Both the GEOS SG-GCM and SG-DAS have been developed at the NASA/Goddard Space Flight Center Data Assimilation Office (DAO) in collaboration with the University of Maryland (Fox-Rabinovitz et al.1997, 2000, 2001, Fox-Rabinovitz 2000, Takacs et al. 1999). In this study, both the model and system with the stretched grid with multiple (four) areas of interest are used for simulation and data assimilation of various anomalous regional climate events occurred during 1998. This is done not as a case study but rather in the context of investigating the potential of the stretched-grid approach for providing regional downscaling to realistic mesoscales while preserving the high quality of global circulation for long-term integrations.

The SG-design with multiple areas of interest is given in Section 2. A brief description of the the basic GEOS GCM and DAS as well as their SG-versions, the GEOS SG-GCM and SG-DAS, are presented in Section 3. The global circulation fields obtained with the SG-GCM and SG-DAS are presented in Section 4. The anomalous regional climate events produced in both simulation and data assimilation modes are analyzed in Section 5. The concluding remarks are given in Section 6.

\section{The design of a stretched-grid with multiple areas of interest}

The original stretched-grid design with one area of interest (Staniforth and Mitchell 1978) has uniform (latitude $x$ longitude) fine regional resolution over the area of interest that has to be a spherical rectangle (Fig. 1a). Outside the area of interest, the grid intervals are increasing or stretching in both latitudinal and longitudinal directions as a geometric progression with the constant local stretching (or geometric progression) factor or the ratio defined as 


$$
R j=D X j / D X j-1,
$$

where DXj and DXj-1 are adjacent grid intervals, and $\mathrm{j}$ is the horizontal index.

Another important SG-parameter is the maximal grid interval on the sphere (in both latitudinal and longitudinal directions) that controls the global accuracy of approximation:

$$
\mathrm{DX} \max =\max (\mathrm{DXj}) .
$$

The SG-design is portable so that the area of interest, i.e. a uniform fine horizontal resolution spherical rectangle, can be allocated over any part of the globe such as the rectangle over the U.S. used in the previous authors' studies with the SG-dynamical core (Fox-Rabinovitz et al. 1997, 2000) and with the SG-GCM (Fox-Rabinovitz 2000, Fox-Rabinovitz et al. 2001).

Note that if the area of interest includes the polar point or even the vicinity of the pole the stretched grid is to be rotated so that, for example, the polar point will be placed on the equator in the rotated coordinates.

In this study, the original SG-design is generalized by introducing multiple areas of interest. The practically meaningful way to do it is as follows. Let us assume that the first area of interest is located in the northwestern global quadrant (Fig. 1b). The second area of interest can be introduced in the southwestern global quadrant by clustering and stretching some latitudes only while keeping the same longitudinal grid-point distribution. Note that the latitudes within the first area of interest are not affected by such a redistribution of the remaining latitudes. As a result, the second area of interest (also a spherical rectangle) is allocated in the Southern Hemisphere south of or 
"down-under" the first area of interest (Fig. 1b). A similar procedure can be applied in the northeastern global quadrant through clustering and stretching some longitudes only while keeping the same latitudinal grid-point distribution. As a result, the third area of interest appeared in the Eastern Hemisphere or eastward of the first area of interest. Evidently, the fourth area of interest will appear in the southeastern global quadrant as an intersection of the above clustered and stretched latitudes and longitudes (Fig. 1b).

Note that in principle the procedure can be continued so that six, eight and more areas of interest can be produced. However, because the same amount of global grid-points is being redistributed to produce the stretched grids, the introduction of too many areas of interest while using moderate SG-parameters (for controlling potential computational problems due to grid irregularity, see the discussion below), has to be stopped at some point. Otherwise, it will evidently result in creating only a formally variable-resolution grid that will actually be very close to an original uniform grid.

It is noteworthy that similar to the original SG-design with one area of interest (Fig. 1a), the local stretching factor $\mathrm{Rj}(1)$ is constant (and the same for the entire globe) for the new SG-design with multiple areas of interest (Fig. 1b). However, Rj could be in principal different for the latitudinal and longitudinal directions. Such an option was not used in this study.

The stretched grid with four area of interest, one within each global quadrant (Fig. 1b), seems to be an optimal SG-design in the following sense. It has more homogeneous distribution of global grid-points than that of the stretched grid with one area of interest (Fig. 1a). Such a global grid-point homogeneity is beneficial for a better representation of global circulation characteristics and for consistent interactions between global and 
regional scales. At the same time, the sizes of the areas of interest have to be adjusted to satisfy the requirements of an optimal/moderate stretching necessary for climate runs.

In order to control undesired computational problems due to grid irregularity, the following constrains have to be imposed on the stretched-grid design (Vichnevetsky 1987, Fox-Rabinovitz 1988, Fox-Rabinovitz et al. 1997). First, the stretching should be uniform, i.e. with $\mathrm{Rj}=$ constant for all $\mathrm{j}$ 's. Second, the stretching has to be well controlled or gradual/moderate in the sense that the local stretching factors should not usually deviate from unity by more than about, $5-10 \%$. This allows one to have fine mesoscale resolution over the area of interest while allocating a significant percentage of the total number of global grid points within the area(s) of interest. This reduces the amount of computations needed over the rest of the globe (e.g. Cote et al. 1993, 1998, Cote1997). Third, to keep the overall accuracy of approximation under control for the moderate stretching strategy mentioned above, the maximal grid intervals have to be not larger than 2-4 degrees to be quite close to the resolution of typical GCMs. This is needed for maintaining a reasonable quality or realistic skill of global simulated fields that is necessary for providing consistent interactions between global and regional scales throughout SG-GCM integrations. Forth, fine regional resolution over the area(s) of interest has to be uniform to avoid any stretching related effects.

It is noteworthy that the strictly controlled SG-parameters needed for the regional climate simulation mode could be relaxed for other modes of integration such as the short-term forecasting (Cote et al. 1993, 1998) and data assimilation modes. 
The choice of stretched-grid parameters depends on a particular model design, configuration, requirements, and modes of integration. It also depends on model's numerical scheme.

The stretched grid used in this study has the same number of grid-points as the global uniform $1 \times 1$ degree grid but redistributed according to the SG-design with multiple (four) areas of interest (Fig. 1b). The areas of interest with approximately $50 \mathrm{~km}$ uniform regional resolution are defined by the following coordinates: $28^{\circ} \mathrm{S}$ to $9^{\circ} \mathrm{S}$ and $21^{\circ} \mathrm{N}$ to $46^{\circ} \mathrm{N}$ in the latitudinal direction; and $125^{\circ} \mathrm{W}$ to $43^{\circ} \mathrm{W}$ and $50^{\circ} \mathrm{E}$ to $120^{\circ} \mathrm{E}$ in the longitudinal direction. As a result, the four areas of interest and their immediate vicinities include the following four large sub-continental scale regions located at each of the four global quadrants: 1 . NW quadrant: the U.S., southern Canada, northern and central Mexico, the Caribbean, and the adjacent Pacific and Atlantic Ocean areas; 2. SW quadrant: Brazil, Peru, Bolivia, northern Argentina, and the adjacent Pacific Ocean area; 3. NE quadrant: the westerm part of the Middle East, northern and central India, China, Northern Indo-China, and the adjacent seas; 4. SE quadrant: the central Indian Ocean, eastern and central Australia, and southern Indonesia. Notice that the tropical parts located between the northern and southern regions are also quite well resolved whereas for the rest of the tropics resolution is refined mostly in the latitudinal direction.

The areas of interest within the stretched grid (Fig. 1b) include the major global mountains (at least their major parts) such as the Rocky Mountains, the Andes, the Himalayas, and the Australian mountains. The North and South African mountains, and the Alps have fine resolution only in the latitudinal direction. The four areas of interest 
also cover the major monsoonal circulations over North America, South America, India, China and China Sea, and Australia and Indonesia.

The stretched grid (Fig. 1b) has moderate stretching parameters suitable for the annual SG-GCM simulation. Although for the SG-DAS run the stretching parameters could be quite relaxed, as mentioned above, they are kept the same for consistent validation purposes. The local stretching factors (Eq.(1)) are about $3.5 \%$ and the maximal grid intervals are about 3 degrees for both latitudes and longitudes. The total global stretching factors or the ratios of maximal to minimal grid intervals are approximately 6 in both the latitudinal and longitudinal directions.

As an option, the spherical grid can be rotated so that the areas of interest are located, for example, about the equator in the rotated coordinates (e.g. Takacs et al. 1994). Such a rotation is not necessary for the stretched grid used in this study with the areas of interest located far away from the polar domains.

\section{A brief description of the GEOS SG-GCM and SG-DAS and the experimental setup}
a. A brief description of the GEOS GCM

The GEOS GCM was developed at the NASA/Goddard Space Flight Center Data Assimilation Office (DAO). The earliest predecessor of the GEOS GCM was developed in 1989 based on the "plug-compatible" concepts outlined in Kalnay et al. (1989). The GEOS GCM was subsequently improved in 1991 (Fox-Rabinovitz, et al. 1991, Helfand et al. 1991). The Relaxed Arakawa-Schubert (RAS) cumulus convective parameterization and the re-evaporation of falling rain are based upon the works of Moorthi and Suarez 
(1992) and Sud and Molod (1988). The long-wave and short-wave radiation is parameterized following Chou and Suarez (1994). The planetary boundary layer and the upper level turbulence parameterizations are based on the level2.5 closure model of Helfand and Labraga (1988) and Helfand et al. (1991). The orographic gravity wave drag parameterization follows Zhou et al. (1995). The model physics is updated throughout integration with different frequencies ranging from every two dynamics time steps for turbulence and gravity wave drag, three dynamics time steps for moist processes (convection and large-scale precipitation) to one hour for short-wave and three hours for long-wave radiation. All model physics updates are prorated and applied at every time step.

The momentum equations used in the GEOS GCM are written in the "vector invariant" form, as in Sadourney (1975) and Arakawa and Lamb (1981), to facilitate the derivation of the energy and potential enstrophy conserving 4th-order differencing scheme. The thermodynamic (potential temperature) and moisture (specific humidity) equations are written in a flux form to facilitate potential temperature and moisture conservation. The Arakawa $\mathrm{C}$-grid is used for horizontal approximation. For vertical approximation, an unstaggered Lorenz (1960) grid in generalized sigma coordinates, is used. The vertical differencing scheme is described in Arakawa and Suarez (1983). The time integration is done with the economical explicit scheme (Schuman1971, Brown and Campana 1978, Fox-Rabinovitz 1974), based on a leap-frog scheme with a time-averaged pressure gradient. The scheme allows one to use approximately twice larger time steps than those of the leap-frog scheme. A complete description of the fourth order finite-difference scheme used in the dynamical core, can be found in Suarez and Takacs (1995). 
In the early 90s, the GEOS GCM was routinely run with $2 \times 2.5$ degree horizontal resolution and 70 layers in the vertical covering the entire tropospheric and stratospheric domain between the surface and the $0.01 \mathrm{hPa}$ level. Since the late $90 \mathrm{~s}$, the GEOS GCM is routinely run with $1 \times 1$ degree horizontal resolution and 48 layers in the vertical covering the same vertical domain. The GEOS GCM was developed and used as a component of the GEOS DAS. It is also used for long-term simulations such as those of the AMIP (Atmospheric Model Intercomparison Project).

\section{b. Configuration of the GEOS SG-GCM}

The SG-GCM is based on the GEOS GCM and uses the variable-resolution stretchedgrids described above. At the current stage of the SG-GCM development, the model has a SG-dynamical core with real orography as described by Fox-Rabinovitz et al. (1997, 2000). Along with introducing a stretched-grid coordinate array, some interpolation techniques depending on a grid definition are modified accordingly.

The numerical scheme of the GEOS GCM, with all its desirable conservation and other properties, remains unchanged when using stretched grids. Two basic horizontal filtering techniques, a refined high-latitude filter (Takacs et al. 1999) and a Shapiro (1970) filter, have been adjusted to variable resolution. They are applied in the model directly to stretched-grid fields. The filtering approach provides a workable monotonic global solution.

The prognostic variables (wind components, temperature, moisture and surface pressure) for the dynamical model state are updated and stored on the model dynamics stretched grid. The diabatic tendencies are updated at the appropriate physical/computational time-scales on their own physical (intermediate uniform) grid. 
Then they are interpolated, prorated per time step and applied at every time step to the model dynamics stretched grid. As a result, the whole integration history resides effectively on the stretched grid. It is noteworthy that resolution used for the intermediate uniform grid for calculating model physics and surface boundary forcing for this study, is $1 \times 1$ degrees. Such an approach is justified by the assumption that model physics and dynamics can be treated at different temporal and spatial resolution. This subject has been discussed by Lander and Hoskins (1997). For a spectral model, they advocate for using coarser resolution for model physics than for model dynamics, and further conclude that similar considerations also apply to finite-difference and finite- element models.

At this stage of the SG-GCM development, implementing model physics on an intermediate uniform resolution grid allows us to avoid some potential complications that may arise from calculating model physics parameterizations on a stretched grid such as, for example, convection in the tropics. It was carefully verified that for such a combination of the SG-model dynamics and intermediate uniform grid model physics, the model physics captures the finer scale patterns produced by the model dynamics on the stretched grid (Fox-Rabinovitz et al. 2001).

\section{c. A brief description of the GEOS SG-DAS}

The GEOS DAS consists of two major components: the GEOS GCM and the analysis system. The GEOS GCM is used for producing first guess or short-term forecast fields and diagnostics between regular, every 6 hour, data insertions. The analysis increments or deviations from the first guess fields are produced every 6 hours in an intermittent analysis cycle. 
The GEOS SG-DAS is based on the basic GEOS DAS. The GEOS SG-GCM is used as a component within the GEOS SG-DAS for producing the background first guess or 6 hour forecast fields. The Physical-space Statistical Analysis System (PSAS) is used for producing analyses within the GEOS SG-DAS. It is based on the concept of minimizing the variance of analysis error. This minimization is achieved through finding an appropriate combination of observation and background fields (e.g. Cohn et al. 1998). The incremental analysis update (IAU) is implemented as a balancing procedure (Bloom et al. 1996).

At this stage of development, the SG-GCM within the SG-DAS is combined with the uniform $1 \times 1$ degree resolution PSAS to avoid the potential complications related to variable- resolution aspects for the statistical models employed by the system. It allows us to use the existing statistical structures of the basic GEOS DAS for the SG-DAS. Note also that model and observational or analysis resolution have not to be necessarily the same. The effective observational resolution depends on the mean distances between observation locations and, therefore, differs for different regions or sub-regions.

It is noteworthy that the variable-resolution SG-GCM is used for producing the first guesses as indicated above and also for the IAU model integrations within 6 hour periods, with analysis increments interpolated on a stretched grid and inserted as a r.h.s. forcing prorated at every time step. As a result, the whole data assimilation procedure history resides effectively on a stretched grid, with all its products, analyses and diagnostics, obtained also on the stretched grid. 


\section{d. Experimental setup}

The surface boundary forcing for the SG-GCM is as follows. Orography is calculated directly on a stretched-grid by averaging, within a grid box, the Navy $1 / 6 \times 1 / 6$ degree surface elevation dataset available from the National Center for Atmospheric Research (NCAR). The grid-box averaged orography is passed through a Lanczos (1966) filter in both latitudinal and longitudinal directions which removes the smallest scales while inhibiting Gibbs phenomena (Takacs et al.1994). The orographic forcing is represented directly on the stretched grid as an integral part of the model dynamics (Fox-Rabinovitz et al. 2000). As a result, the fine regional resolution orographic forcing and its gradients make a significant impact and can lead to improvements in regional climate simulation with enhanced mesoscale resolution.

As described in Section 2, the stretched grid is characterized by the well controlled SG-parameters with a moderate local stretching factor about $3.5 \%$ and a maximum grid interval about 3 degrees. The stretched grid with $0.5 \times 0.625$ degree or approximately $50 \mathrm{~km}$ regional resolution has five times less grid-points than that of the global uniform $50 \mathrm{~km}$ resolution grid.

The NCEP data analyses are used for surface boundary forcing, namely, the weekly analyses of SST, snow, and sea-ice distributions, and the monthly analyses of soil moisture. The SST forcing with $1 \times 1$ degree resolution is used. Other surface forcing components (the snow, sea-ice, and soil moisture distributions), are available only for $2 \times 2$ degree resolution and are interpolated onto the $1 \times 1$ degree grid used for calculation of model physics. The continents and, therefore, the land-sea differences are resolved at $1 \times 1$ degree resolution as well. 
The SG-GCM and SG-DAS experiments have been started from initial conditions at $12 Z 15$ October 1997 and 00Z 1 November 1997, correspondingly, and continued through December 1998. The initial conditions have been obtained from the GEOS SG-GCM and SG-DAS runs, respectively, started two weeks earlier to avoid the initial spin-up effects. Prognostic and time-averaged (within 3 or 6 hour intervals) diagnostic fields like precipitation are stored every 6 hours.

A strict validation approach is used in this study for comparing the SG-GCM simulations against the SG-DAS analyses and diagnostics produced with the same variable resolution enhanced over the areas of interest. Using the SG-DAS assimilated products over the U.S. and other high density observational networks allows us to calculate the mean errors or biases as the deviations of simulated fields from the corresponding verifying SG-DAS analyses. The SG-DAS analyses are compared with the uniform-grid ECMWF reanalyses as a reference or "a second opinion" as well. Both stretched-grid simulated and assimilated precipitation is validated against independent gauge precipitation data, with high, 0.25 degree, resolution available over the U.S., and coarse, 2 degree, resolution available over the rest of the globe (Xie-Arkin 1996).

\section{Global fields}

a. Prognostic variable spectra

Preserving the high quality or integrity of global circulation necessary for a consistent representation of global and regional scales within SG-GCMs and SG-DASs, is an important feature of the SG-approach. An example of spherical harmonics spectra of the $500 \mathrm{hPa}$ kinetic energy averaged over a three month period, AMJ (April-May-June) 1998, 
for the SG-GCM simulation, SG-DAS assimilation, and ECMWF reanalyses (as a reference), is presented in Fig. 2. As indicated in Sections 2 and 3 the SG-GCM and SG-DAS have $50 \mathrm{~km}$ regional resolution with the maximum grid interval less than 3 degrees whereas the ECMWF reanalyses are produced with $1 \times 1$ degree uniform global resolution.

The SG-GCM and SG-DAS spectra are practically indistinguishable from each other. The close similarity of the SG-GCM spectrum to that of the verifying SG-DAS analyses for all scales shows that the SG-GCM simulation with no data impact is capable of maintaining the correct spectral distribution. All three spectra are very close to each other for long and medium wave spectral ranges. The small scales are stronger for the SG-GCM and SG-DAS spectra than for the ECMWF reanalysis spectrum due to using higher regional resolution. This shows the appropriate sensitivity to resolution in the small-scale range for the SG-GCM and SG-DAS fields. Most importantly, using the SG-approach for both the model and system has not resulted in any deterioration or compromise of the spectral representation for all resolved scales.

It is noteworthy that other spectra produced for different fields (heights, temperature, etc.), seasons, and model levels reveal the same close similarity to each other. Such an important property of the SG-GCM and SG-DAS of preserving the spectral distributions allows us to adequately reproduce the consistent interactions between different scales.

\section{b. Prognostic variable distributions}

Let us consider first the AMJ zonal mean vertical distributions of the zonal wind component for the SG-GCM, SG-DAS, and ECMWF reanalyses (Fig. 3). All three distributions are similar to each other. The jet cores are located about $200 \mathrm{hPa}$ in the 
vertical, and about $30^{\circ} \mathrm{N}$ and $30^{\circ} \mathrm{S}$ for the Northern and Southern Hemisphere, respectively. The jet core centers are also close to each other, with $25 \mathrm{~m} / \mathrm{s}$ in the Northern and $35 \mathrm{~m} / \mathrm{s}$ in the Southern Hemisphere. It is noteworthy that the similarity of patterns and such features as gradients, and the center positions and strengths, is obtained for zonal mean distributions of other prognostic variables for this and other seasons.

The horizontal distributions of the AMJ $500 \mathrm{hPa}$ heights for the SG-GCM and SGDAS, as well as their difference or bias are presented in Fig. 4. The fields are close to each other (Fig. $4 \mathrm{a}$ and b). It is noteworthy that the SG-DAS distribution is also very close to that of the ECMWF reanalyses (not shown), with the differences within $5 \mathrm{~m}$ everywhere outside Antarctica. They go there up to $40 \mathrm{~m}$ due to the different treatment of the polar problem in the models used within the DASs. The SG-GCM simulation bias or the differences between the SG-GCM and SG-DAS fields are within $20-40 \mathrm{~m}$ over the four areas of interest (Fig. 4 c). Outside the four areas of interest the bias is within 20-60 $\mathrm{m}$, with the exception of the polar domains where it goes up to $100 \mathrm{~m}$. It is worth reminding that the polar rotation is not used for the SG-GCM simulation and the polar problem is stronger for the case although contained well within the polar domains.

Let us consider the AMJ $850 \mathrm{hPa}$ zonal wind component produced by the SG-GCM and SG-DAS versus that of the ECMWF reanalysis (Fig. 5) presented here as a reference. The simulated and assimilated global distributions of zonal winds (Fig. $5 \mathrm{a}$ and b) are very close to each other as well to that of the ECMWF reanalysis (Fig. $5 \mathrm{c}$ ). The biases for the simulated zonal winds or their deviations from the assimilated zonal winds (not shown) are about $1.2 \mathrm{~m} / \mathrm{s}$ within the areas of interest. The biases are limited to a few $\mathrm{m} / \mathrm{s}$ for the 
entire globe outside the polar domains where they are a bit larger what is consistent with the height bias distribution shown above (Fig. 4).

The limited biases and similarity of the SG-GCM simulation fields to the verifying SG-DAS analyses (Figs. 4) as well as to the ECMWF reanalyses (used as a reference)

(Fig. 5) for the height and all other prognostic variables, show a high quality of the global circulation produced by the SG-GCM simulation. Even a higher quality is obtained for the SG-DAS. The regional downscaling properties of the simulated and assimilated fields and diagnostics will be discussed in detail in the next section.

It is noteworthy that using the stretched grid with four areas of interest instead of one area of interest provides a more homogeneous distribution of global grid-points that in turn results in producing better global circulation characteristics. In particular, such features obtained for the stretched grid with one area of interest over the U.S. (Fig. 1 a), as an equator-ward pattern shift in the Southern Hemisphere attributed to the impact of coarser resolution there (e.g. Fox-Rabinovitz et al. 1997, 2000), do not appear for the simulated and assimilated fields produced with the stretched grid with four areas of interest due to more homogeneous global variable resolution (Fig. 1 b).

The high quality of the global circulation characteristics obtained for both the SG-GCM and SG-DAS laid a solid foundation for providing consistent interaction between global and regional scales within the SG-approach. 


\section{Anomalous regional climate events of 1998}

This section contains the discussion on the major anomalous regional climate events occurred during 1998. The description of the events is presented in Bell et al. (1999). We will show below the results of the SG-GCM simulation and the SG-DAS assimilation and analyze them in terms of representing the regional events in the context of the SG-approach but not as the case studies. We will analyze the major regional climate events occurred within all four global quadrants containing four areas of interest). These large areas with enhanced regional resolution and their immediate vicinities cover practically all the major regional climate events of 1998 . We will also analyze an event occurred outside the areas of interest (over central Africa) where resolution is coarser than that over the areas of interest. We will investigate the quality of the SG-GCM simulation versus the SG-DAS verifying analyses, and the ability of both of them to provide efficient downscaling to mesoscales. We will also analyze the pattern similarity of both the SG-GCM simulation and the SG-DAS assimilation fields versus that of independent observations (gauge precipitation data) and the reference (ECMWF) reanalyses.

a. The 1998 spring AMJ (April-May-June) events over the U.S.

Let us start our discussion with analyzing precipitation produced by the SG-GCM simulation and SG-DAS assimilation.

The major 1998 spring or April-June (AMJ) U.S. events were the Midwest and Northeast flood and the drought in the South. The drought area extended through the major parts of the south-central and southeastern U.S. (Fig. $6 \mathrm{c}$ ), with the statewide record low rainfall for New Mexico, Texas, Louisiana, and Florida since 1895 (Bell et al. 
1999). The drought was associated with record high temperatures from New Mexico to Florida, especially in May-June. However, for the major parts of the western, Midwestern, and northeastern U.S. the flood or above-normal precipitation occurred for the spring season, especially over Ohio, Tennessee, the Appalachians, and lower Northeast (Bell et al. 1999). Note that both the SG-GCM simulation and SG-DAS assimilation started in November1997 so that by June 1998 they were continued for eight months.

The AMJ simulated, assimilated, and NCEP gauge precipitation (the later only over the U.S.) is shown in Fig. 6. Simulated precipitation over the south-central and southeastern U.S. is overestimated by $\sim 1-2 \mathrm{~mm} /$ day (Fig. 6 a) compared to gauge data (Fig. $6 \mathrm{c}$ ). The pattern over the Midwest and northeastern U.S. shows some strong precipitation or flood conditions (Fig. 6 a) that is generally consistent with gauge data (Fig. 6 c). The maximum Midwest simulated precipitation (Fig. 6 a) is quite consistent with that of assimilated precipitation (Fig. 6 b) but located west of that of gauge data (Fig. 6 c). Simulated precipitation over the northwestern and western U.S. (Fig. 6 a) is quite close to that of gauge data (Fig. $6 \mathrm{c}$ ).

The SG-DAS assimilated precipitation pattern (Fig. 6 b) is similar to that of gauge data (Fig. $6 \mathrm{c}$ ) although the assimilated rainfall over the south-central and southeastern U.S. is overestimated by approximately $1 \mathrm{~mm}$ /day. Over Texas and Oklahoma it is overestimated even more. However, over the western, Midwestern, and northeastern U.S. the assimilated rainfall is quite close to that of gauge data (Fig. $6 \mathrm{c}$ ). The realistic mesoscale features mostly associated with orography are produced over the Appalachians, especially over Tennessee, Kentucky, and the northeastern U.S., and also over the 
northwestern U.S. and northern California. It is noteworthy that the SG-GCM simulated and SG-DAS assimilated precipitation patterns (Fig. $6 \mathrm{a}$ and b) are quite close to each other although assimilated precipitation (Fig. 6 b) is closer to gauge data (Fig. $6 \mathrm{c}$ ).

The ability of the SG-GCM and SG-DAS to reproduce seasonal changes, is presented in Fig. 7. It shows the change or difference between the anomalous spring (AMJ) and close-to-normal winter (JFM) precipitation. Note that negative (positive) differences indicate the decrease (increase) of the spring (AMJ) versus winter (JFM) precipitation. The seasonal rainfall change is well reproduced by both the SG-GCM simulation (Fig. 7 a) and SG-DAS assimilation (Fig. 7 b) as compared to that of gauge data (Fig. 7 c). More specifically, the negative differences over the Gulf and east coast states, extending from east Texas to Virginia (Fig. 7 c), appear in both the simulated (Fig. 7 a) and assimilated (Fig. 7 b) fields. The magnitude of the negative values as well as the area containing the negative differences over Texas and Oklahoma are underestimated as compared to those of Fig. $7 \mathrm{c}$. The negative changes over the western parts of Washington and Oregon states as well as the state of California (Fig. $7 \mathrm{c}$ ) are produced in both simulated (Fig. 7 a) and assimilated (Fig. 7 b) difference fields although they are underestimated and do not include the southern California area. The negative differences over Arizona (Fig. 7 c) are reproduced in the assimilated fields (Fig. 7 b) but not in the simulated ones (Fig. 7 a). It is noteworthy that the negative differences over southwestern Canada and those of adjacent to the west and east coasts in the Pacific and Atlantic Oceans, correspondingly, are similar for simulated (Fig. 7 a) and assimilated fields (Fig. 7 b). Underestimation of negative changes for simulated and assimilated fields indicated above is partly due to their coarser resolution compared to that of gauge data. 
The positive changes over the rest of the U.S., especially over the Midwest, Northeastern, and Western states, in simulated and assimilated fields (Fig. $7 \mathrm{a}$ and b) are close to those of gauge data (Fig. 7 c). Generally, the seasonal changes are well represented in simulated and especially assimilated fields.

Let us consider now the patterns, biases and anomalies obtained for prognostic variables for the SG-GCM simulation and SG-DAS assimilation. The simulation biases are calculated against the corresponding assimilated fields whereas the anomalies are obtained using the ECMWF climatology for 1979-1997.

The $850 \mathrm{hPa}$ zonal winds for simulated, assimilated, and $1 \times 1$ degree resolution ECMWF reanalyses fields (as a reference) are shown in Fig. 8 a, b, c whereas the SG-GCM simulation bias calculated against the SG-DAS analyses is presented in Fig. 8 d. All the field patterns (Fig. 8 a, b, c) are similar, and those of the assimilated and reference analyses (Fig. 8 b, c) are very close to each other. The impact of the mesoscale Appalachian mountains is stronger in the simulated and assimilated fields (Fig. 8 a, b) than in the coarser resolution ECMWF reanalysis field (Fig. $8 \mathrm{c}$ ), especially over West Virginia, Tennessee and their vicinity. The gradients are a bit stronger for the assimilated versus reanalysis fields (Fig. $8 \mathrm{~b}, \mathrm{c}$ ). All that is consistent with higher, $50 \mathrm{~km}$, regional resolution used for the SG-GCM and SG-DAS. The bias (Fig. $8 \mathrm{~d}$ ) over the U.S. and major part of Canada is small and limited to $1-2 \mathrm{~m} / \mathrm{s}$. Off the U.S. east and west coasts, the bias is larger over the Atlantic ocean due to some pattern shift in a strong gradient zone around $30^{\circ} \mathrm{N}$.

The $850 \mathrm{hPa}$ zonal wind anomalies for the above fields are presented in Fig. 9. The anomalies over the land and the part of the Pacific Ocean adjacent to the west coast are 
close to each other. They differ for the simulated field (Fig. 9 a) over the part of the Atlantic Ocean adjacent to the U.S. east coast. This difference is consistent with the aforementioned larger bias for the area (Fig. 8 d). All the three anomaly patterns (Fig. 9 a, b, c) are quite similar, especially in terms of distributions of the below-normal (negative) and above-normal (positive) values. The mesoscale features along the Appalachians, especially over West Virginia and its vicinity, are better presented (stronger) in the assimilated field (Fig. 9 b) obtained with higher regional resolution than of the ECMWF reanalysis (Fig. 9 c). Also, the gradients around the $100^{\circ} \mathrm{E}$ longitude, east of the Rocky Mountains, are stronger for the assimilated field (Fig. $9 \mathrm{~b}$ ) compared to those of the reanalysis (Fig. $9 \mathrm{c}$ ).

We conclude the discussion of the AMJ fields for the region by showing the simulated and assimilated 2-meter temperatures and the simulated temperature bias or deviation from the verifying SG-DAS analyses (Fig. 10). The simulated and assimilated 2-meter temperatures (Fig. $10 \mathrm{a}, \mathrm{b}$ ) are very close to each other so that the bias over the U.S. and its large vicinity is mostly within $1^{\circ} \mathrm{K}$ and does not exceed $2^{\circ} \mathrm{K}$ (Fig. $10 \mathrm{c}$ ). The mesoscale features over the Appalachians, especially over West Virginia, around the northeastern U.S. coast, and the west coast, as well as the centers over Colorado and Wyoming, are similar for simulated and assimilated fields (Fig. $10 \mathrm{a}, \mathrm{b}$ ) what is supported by a very limited bias ((Fig. $10 \mathrm{c})$.

It is noteworthy that the pattern similarities indicated above take place for other prognostic variables and at different levels as well.

b. The 1998 MAM (Mach-April-May) Mexican drought 
The MAM spring season is usually dry in Mexico but in 1998 the total precipitation was significantly, almost $80 \%$, below normal for most of the country (Bell at al. 1999). The simulated and assimilated MAM precipitation over Mexico against that of NCEP gauge data at coarser, 2 degree, resolution is shown in Fig. 11. The severe drought event (Fig. $11 \mathrm{c}$ ) is well represented in assimilated precipitation (Fig. 11 b). Simulated precipitation (Fig. 11 a) is significantly overestimated (and close to normal) in eastern Mexico. However, the drought is well simulated in western Mexico (Fig. 11 a). It is noteworthy that the area of interest with enhanced regional resolution in the northwestern global quadrant (Fig. 1 b) does not include southern Mexico where resolution is getting coarser due to the grid stretching procedure. This could cause, at least partly, the above overestimation of simulated precipitation in the southeastern Mexico (Fig. 11 a).

$$
\text { c. The } 1998 \text { MAM events in South America }
$$

The following anomalous events occurred in MAM over South America. Over northern South America, except for Venezuela, western parts of western Ecuador and northern Peru precipitation was bellow normal. Rainfall deficits also occurred in some parts of northeastern Brazil. On the other hand, excessive precipitation was observed over western Peru and Ecuador that resulted in severe flooding. Over the usually dry coastal Peru, a large rainfall anomaly took place. The above-normal rainfall also occurred for the season over southern Brazil, Paraguay, Uruguay, and northeastern Argentina that resulted in major flooding in the area (Bell et al. 1999).

The simulated and assimilated precipitation anomalies for MAM 1998 are shown in Fig. 12 a, b and NCEP gauge data at 2 degree resolution in Fig. 12 c. Over northern South America (north of approximately $20^{\circ} \mathrm{S}$ ) the anomalies are predominantly below normal 
(negative) (Fig. 12 c). Over Venezuela, the Brazilian northern coast near the French Guiana border (around $3^{\circ} \mathrm{N}$ and $53^{\circ} \mathrm{W}$ ), and over the coastal area around the Peru and Ecuador border, the above-normal (positive) anomalies occur (Fig. $12 \mathrm{c}$ ). The strong positive anomalies are observed over Paraguay, Uruguay, southeastern Brazil, and northeastern Argentina (Fig. $12 \mathrm{c}$ ).

The simulated and assimilated precipitation patterns (not shown) are quite similar to that of gauge data for the season.

The simulated and assimilated precipitation anomalies are generally larger (Fig. $12 \mathrm{a}, \mathrm{b}$ ) than those of coarser resolution gauge data (Fig. 12 c), especially over the northern and western coastal areas and over the Andes. The simulated and assimilated precipitation anomalies are close to each other (Fig. 12 a, b). The negative anomalies occur in central and northeastern Brazil whereas the positive anomalies dominate over the areas along the northern coasts of Brazil and Venezuela as well as the western coasts from Columbia to northern Chile and in southern Chile (Fig. 12 a, b). The strong positive anomaly over Paraguay, Uruguay, southeastern Brazil, and northeastern Argentina (Fig. $12 \mathrm{c}$ ) is present in simulated (Fig. 12 a) and especially well represented in assimilated (Fig. 12 b) precipitation anomalies. The below-normal precipitation is correctly simulated over northern Peru (Fig. $12 \mathrm{a}$ and $\mathrm{c}$ ).

\section{d. The 1998 summer flood in China}

During June-September (JJAS) 1998 above-normal precipitation occurred over the Yangtze River basin. The most excessive rainfall occurred in June and July. The largest anomalies were observed over the eastern part of the basin. The onset of the first major flooding of the Yangtze River began in early July (Bell et al. 1999). 
During July the largest rainfall as well as rainfall anomalies were observed mostly in the eastern parts of the basin, and also in the central and southwestern parts of China (Fig. $13 \mathrm{c}$ and Fig. $14 \mathrm{c}$ ). Simulated and assimilated precipitation patterns (Fig. $13 \mathrm{a}, \mathrm{b}$ ) are similar and show strong precipitation over the above parts of China, in a good general agreement with gauge data (Fig. $13 \mathrm{c}$ ). The simulated and assimilated precipitation amounts are larger compared to that of coarser resolution gauge data.

The simulated (Fig. 14 a) and assimilated (Fig. 14 b) July precipitation anomalies are close to each other and compare reasonably well over the flood area with that of gauge data (Fig. 14 c). The simulated precipitation anomaly for the central and western parts of the basin is slightly shifted northward by approximately 1-2 degrees. The precipitation anomalies over the China east coast are overestimated in simulated and assimilated precipitation.

The severe summer flood in China, one of the major anomalous regional events of 1998, appeared to be quite well represented in both simulated and especially assimilated precipitation and precipitation anomaly fields.

\section{e. Precipitation over Australia}

Tropical climate in Northern Australia is characterized by a well-defined rainy period extending from December through April. For the rainy season in 1998 above-normal rainfall was observed around Darwin and in the southern part of the Cape York Peninsula. However, for the areas, the above-normal precipitation occurred mostly during December and January. During the rainy season precipitation was below normal along the east coast and across the parts of west and northwest. Above-normal precipitation occurred in eastern and also in central and western Australia during April through 
November of 1998. Southeastern Australia had below-normal precipitation during almost the entire year, especially east and southeast from Melbourne (Bell et al. 1999).

The simulated and assimilated precipitation anomalies as well as those of coarser, 2 degree, resolution NCEP gauge data for December 1997 and January1998 (DJ), are shown in Fig. 15. The anomaly patterns are quite similar. The anomalies are predominantly above normal (positive) over northern Australia (northward of $20^{\circ} \mathrm{S}$ ), with exception of the northern part of the Cape York Peninsula and an area around Darwin (Fig. 15 c). The simulated and especially assimilated precipitation anomalies show similar distribution for the areas (Fig. $15 \mathrm{a}, \mathrm{b}$ ). The below-normal (negative) anomalies occur over the eastern and southeastern coast, and the northwestern coast (Fig. $15 \mathrm{c}$ ). These features are also represented in the simulated and especially in assimilated precipitation anomalies (Fig. $15 \mathrm{a}, \mathrm{b}$ ). However, the simulated anomalies near the east coast show the negative anomalies underestimated and positive anomalies overestimated (Fig. 15 a). It is noteworthy that for the next two month of the rainy season (February and March), the below-normal precipitation anomalies over the entire eastern Australia are adequately represented not only in assimilated but also in simulated precipitation anomalies (not shown).

The simulated, assimilated and gauge data precipitation anomalies for the period from April through November 1998 are presented in Fig. 16. The above-normal (positive anomaly) precipitation in eastern, and also in central and western Australia (Fig. 16 c) is adequately represented in both the simulated and assimilated precipitation anomalies (Fig. 16 a, b). The below-normal (negative anomaly) precipitation was obtained in the assimilated precipitation anomalies around Melbourne (Fig. 16 b). 
It is noteworthy that the simulated and assimilated anomalies over the entire area of interest in the global southeastern quadrant that includes the part of the Indian Ocean west of Australia (Fig. 1b), are adequately represented and similar to those of gauge data for both the 1998 rainy and dry seasons (not shown).

f. The 1998 JJAS (June-September) Indian summer monsoon

Let us consider now the results obtained for the regions that are only partly included into an area of interest (like the Indian region used in this subsection) or located completely outside an area of interest (like the African Sahel area used in the next subsection $5 \mathrm{~g}$ ). Such a discussion will allow us to estimate the quality of simulated and assimilated fields for the regions of the globe with different resolution within a stretched grid. The southern part of the Indian region shown in Fig. 17 is located outside the area of interest in the northeastern global quadrant for the stretched grid used for the study (Fig. 1 b).

It is noteworthy that due to the poor quality of some conventional data over the Indian region some significant portion of them were rejected by the analysis quality control procedure that affected negatively the quality of assimilated fields.

The Indian monsoon usually lasts from June to September (JJAS). During the period, the western and central India receives about $90 \%$, and southern and northwestern India receives about $50-75 \%$ of their total respective annual precipitation. The monsoon peak occurs in July-August.

The 1998 monsoon precipitation was quite close to normal. Rainfall over India was near-normal during June and July 1998 and became above-normal during August and September, and even October 1998. The above-normal JJAS precipitation occurred in 
western India mostly around the west coast, in the area around the southern rim of the Himalayas, and over Sri Lanka and the southeastern Indian coast (Fig. 17 c).

The gauge precipitation distribution for the region obtained at coarse resolution of 2 degrees is shown in Fig. 17 c. Both simulated and assimilated precipitation (Fig. 17 a, b) have patterns similar to each other and to that of gauge data (Fig. 17 c). However, simulated precipitation around the Indian west coast and over the Bay of Bengal is overestimated (Fig. 17 a). Both simulated and assimilated precipitation patterns (Fig. 17 a, b) show the extremes around Sri Lanka and in southeastern India that are similar but overestimated as compared to those of gauge data (Fig. $17 \mathrm{c}$ ). Over the southern rim of the Himalayas, simulated and assimilated precipitation (Fig. 17 a, b) seem to be also overestimated compared to gauge precipitation (Fig. 17 c). However, it is possible that the above centers are underestimated in the coarse resolution precipitation distribution (Fig. 17 c).

Generally, simulated and assimilated precipitation for the region is quite realistic in spite of having coarser resolution in its southern part. Still, this feature has probably contributed to overestimation of simulated precipitation in the southern part of the region.

g. The 1998 JJAS rainfall over the African Sahel area

The African Sahel region in western Africa $\left(8^{\circ}-18^{\circ} \mathrm{N}, 17^{\circ} \mathrm{W}-20^{\circ} \mathrm{E}\right)$ is not included into any of four areas of interest of the stretched grid used in this study (Fig. 1b). However, it still makes sense to analyze the quality of precipitation produced by the SG-GCM simulation and SG-DAS assimilation for the region with coarser resolution within the stretched grid. 
The rainy season for the area is June through September, during which approximately $90 \%$ of annual precipitation occurs. The JJAS precipitation was close to normal for 1998 .

The JJAS simulated, assimilated, and gauge precipitation for the region and its vicinity is shown in Fig. 18. The rainy season pattern (Fig. $18 \mathrm{c}$ ) is generally represented in simulated and assimilated precipitation (Fig. $18 \mathrm{a}, \mathrm{b}$ ). Also, the desert conditions north of $15^{\circ} \mathrm{N}$, and intensive precipitation over the western Ethiopia mountains (Fig. $18 \mathrm{c}$ ) are produced in both quite similar simulated and assimilated precipitation patterns (Fig. $18 \mathrm{a}$, b). However, simulated precipitation (Fig. 18 a) is overestimated compared to that of assimilated and gauge data (Fig. $18 \mathrm{~b}, \mathrm{c}$ ). Both simulated and assimilated precipitation failed to produce strong precipitation near the Gulf of Guinea coast (Fig. $18 \mathrm{c}$ ).

Therefore, even for the region with coarser resolution within the stretched grid both the SG-GCM and SG-DAS are still capable of producing quite realistic seasonal precipitation and its anomaly distributions.

\section{Concluding remarks}

Introduction of the new design of the stretched grid with multiple areas of interest allowed us to study simultaneously the variety of anomalous regional climate events of 1998 at mesoscale resolution. Both the SG-GCM simulation and SG-DAS assimilation products obtained with $50 \mathrm{~km}$ regional resolution are used in the study.

1. The new stretched-grid design with multiple (four) areas of interest has been introduced into the SG-GCM and SG-DAS. The areas of interest with enhanced regional resolution are located within each global quadrant that makes the grid-point global distribution more homogeneous than that of the stretched grid with one area of interest. 
Such a homogeneity of a grid-point distribution affects positively the overall quality of global simulated and assimilated products.

2. The global fields and diagnostics are well reproduced by the SG-GCM simulation and SG-DAS assimilation. Their spectra are very close for all spectral ranges: the long-, medium-, and short-wave ones. The spectra are also close to that of the reference $1 \times 1$ degree ECMWF reanalyses except for the shortest waves or mesoscales for which the stretched-grid spectra show larger energy due to higher resolution used for the large regions of interest.

The global zonal mean vertical distributions of prognostic variables are close to those of the reference $1 \times 1$ degree ECMWF reanalyses. The same is true for horizontal distributions of the prognostic and diagnostic fields. All that confirms that the high quality global characteristics are obtained for simulated and assimilated fields.

3. The major anomalous regional climate events of 1998 produced by the SG-GCM simulation and SG-DAS assimilation for each of the four global quadrants, are discussed in terms of precipitation and prognostic field products.

The following events are included into the discussion: the spring (AMJ) flood over the Midwestern and northeastern U.S., and the drought over the south-central and southeastern U.S.; the MAM drought over Mexico; the MAM precipitation over South America; the severe summer flood in China; the Indian summer (JJAS) monsoon; the Australian precipitation; and the JJAS precipitation over the African Sahel region.

For all of the events the simulated and assimilated precipitation and/or precipitation anomaly patterns appeared to be close to each other and also close in many details to gauge precipitation data. Simulated precipitation is sometimes overestimated compared to 
that of assimilated or coarse resolution gauge data precipitation, especially outside the areas of interest. Assimilated precipitation compares generally well with gauge data. The mesoscale features are adequately produced for both simulated and assimilated precipitation. Other diagnostic and prognostic variables at different levels compare well with verifying data.

All that shows the success of the SG-GCM simulation and SG-DAS assimilation in terms of the efficient downscaling to realistic mesoscales while preserving the high quality of global circulation. It resulted in an adequate representation of the various anomalous regional climate events occurred in 1998. Evidently, the quality of assimilated products is higher than that of simulated ones.

The obtained results show a high potential of the stretched-grid approach for regional applications and open the opportunity for using both the SG-GCM and SG-DAS for the variety of regional climate and climate change studies.

Acknowledgments: The authors would like to thank Dr. U. Stein and Mr. M.

Gamazaychkov for implementation of a grid generator. The authors would like to acknowledge the support of the study by Dr. K. Bergman and Dr. Y. Sud of NASA, Dr. D. Bader of DOE, and Dr. J. Fine of NSF provided through the NASA, DOE, and NSF grants.

\section{References}

Arakawa, A. and V. R. Lamb: A potential enstrophy and energy conserving scheme for the shallow water equations. Mon. Wea. Rev., 109, 18-36, 1981.

Arakawa, A. and M. J. Suarez: Vertical differencing of the primitive equations in sigma coordinates. Mon. Wea. Rev., 111, 34-45, 1983. 
Bloom, S. C., L. L. Takacs, A. M. daSilva, and D. Ledvina: Data assimilation using incremental analysis updates Mon. Wea. Rev., 124(6), 1256-1271, 1996.

Brown, J. A., and K. Campana: An economical time differencing scheme for numerical weather prediction. Mon. Wea. Rev., 106, 1125-1136, 1978.

Chou M.-D., and M. J. Suarez: An efficient thermal infrared radiation parameterization for use in GCMs. NASA Tech. Memo. 104606, v.3, 85 pp., 1994 [Available from NASA/GSFC Data Assimilation Office, Greenbelt, MD 20771]

Cohn, S. E., A. daSilva, J. Guo, M. Sienkiewicz, and D. Lamich: Assessing the effects of data selection with the DAO physical-space statistical analysis system. Mon. Wea. Rev., 126, 221-234, 1998.

Cote J., M. Roch, A. Staniforth, and L. Fillion: A variable-resolution semi-Lagrangian finite-element global model of the shallow-water equations. Mon. Wea. Rev., 121, $231-243,1993$.

Cote, J.: Variable resolution techniques for weather prediction. Meteor. Atmos. Phys., $63,31-38,1997$.

Cote, J., S. Gravel, A. Metot, A. Patoine, M. Roch, and A. Staniforth: The operational CMC/ MRB Global Environmental Multiscale (GEM) model. Part 1: Design Considerations and Formulation, Mon. Wea. Rev., 126, 1373-1395, 1998.

Courtier, P., and J.-F.Geleyn: A global numerical weather prediction model with variable resolution: application to the shallow-water equations. Q. J. Roy. Met. Soc., 114, 1321-1346, 1988.

Deque, M., and J. P. Piedelievre: High resolution climate simulation over Europe. Climate Dynamics, 11, 321-339, 1995. 
Deque, M., P. Marquet, and R. Jones: Simulation of climate change over Europe using a global variable resolution general circulation model. Climate Dynamics, 14, 173-189, 1998.

Deque, M.: Regional models. Numerical Modeling of the Global Atmosphere in the Climate System. P. Mote and A. ONeill (eds). Kluwer Academic Publishers, 403-418, 2000.

Dickinson, R.E.,R.M.Errico,F.Giorgi,G.T.Bates: A regional climate model for the Western United States, Clim.Change, 15, 383-422, 1989.

Fox-Rabinovitz, M. S.: Economical explicit and semi-implicit integration schemes for forecast equations. Sov. Met. Hydrol., 11, 11-19, 1974.

Fox-Rabinovitz, M. S.: Dispersion properties of some regular and irregular grids used in atmospheric models. Proc. 8th Conf. on Numerical Weather Prediction, Baltimore, AMS, 784-789, 1988.

Fox-Rabinovitz, M., H. M. Helfand, A. Hou, L. L. Takacs, and A. Molod: Numerical experiments on forecasting, climate simulation and data assimilation with the new 17 layer GLA GCM. Ninth Conference on Numerical Weather Prediction. 21-25 October 1991, Denver, CO, 506-509, 1991.

Fox-Rabinovitz, M. S., L.V. Stenchikov, M. J. Suarez, L. L. Takacs: A finite-difference GCM dynamical core with a variable resolution stretched-grid, Mon. Wea. Rev., Vol. 125, No. 11, 2943-2968, 1997.

Fox-Rabinovitz, M. S., L.V. Stenchikov, M. J. Suarez, L. L.Takacs, and R.C. Govindaraju: An uniform and variable resolution stretched-grid GCM dynamical core with real orography, Mon. Wea. Rev., Vol. 128, No. 6, 1883-1898, 2000. 
Fox-Rabinovitz, M.S., L.L. Takacs, and M.J. Suarez: A Variable Resolution Stretched

Grid GCM: Regional Climate Simulation. Mon. Wea. Rev., Vol. 129, No. 3, pp. 453-469, 2001.

Giorgi,F.: Simulation of regional climate using a limited area model nested in a GCM. J. Climate, 3, 941-963, 1990.

Juang, H.-M. H., and M. Kanamitsu: The NMC nested regional spectral model. Mon. Wea. Rev., 122, 3-26, 1994.

Hardiker, V.: A global numerical weather prediction model with variable resolution. Mon. Wea.Rev., 125, 349-360, 1997.

Held, I. M., and M. J. Suarez: A benchmark calculation for the dry dynamical cores of atmospheric general circulation models. Bull. Amer. Meteor. Soc., 75, 1825-1830, 1994. Helfand, H. M., and J. C. Labraga: Design of a non-singular level 2.5 second-order closure model for the prediction of atmospheric turbulence. J. Atmos. Sci., 45, 113-132, 1988.

Helfand, H. M., M. Fox-Rabinovitz, L. Takacs, and A. Molod: Simulation of the planetary boundary layer and turbulence in the GLA GCM. Proceedings of the AMS Ninth Conference on Numerical Weather Prediction, 21-25 October1991, Denver, CO, 514-517, 1991

Kalnay, E., M. Kanamitsu, J. Pfaendtner, J. Sela, M. Suarez, J. Stackpole, J. Tuccillo, L. Umscheid, and D. Williamson: Rules for the interchange of physical parameterizations, Bull. Am. Met. Soc., 70, 620-622, 1989.

Lanczos C.: Discourse of Fourier Series. Hafner Publishing, New York, 255 pp., 1966. 
Lander, J., and B.J. Hoskins: Believable scales and parameterizations in a spectral model.Mon.Wea. Rev., 125, 292-303, 1997.

Lorenz, E. N.: Energy and numerical weather prediction. Tellus, 12, 364-373, 1960. McGregor, J. L., and J. J. Katzfey: Simulating typhoon recurvature with a variable resolution conformal-cubic model. In Research Activities in Atmospheric and Oceanic Modeling, Report No.28 (ed. H.Ritchie), WMO/TD-No.942, 3.19-3.20, 1998.

Mesinger, F., 2001: Limited Area Modeling: Beginnings, state of the art, outlook. 50th Anniversary of Numerical Weather Prediction Commemorative Symposium, Book of Lectures. Potsdam, 9-10 March 2000, A. Spekat, Ed., European Meteorological Society, 91-118. [Available from American Meteorological Society]

Moorthi, S., and M. J. Suarez: Relaxed Arakawa Schubert: A parameterization of moist convection for general circulation models. Mon. Wea. Rev., 120, 978-1001, 1992.

Paegle, J.: A variable resolution global model based upon Fourier and finite-element representation. Mon. Wea. Rev., 117, 583-606, 1989.

Sadourney, R.: The dynamics of finite difference models of the shallow water equations, J. Atmos. Sci., 32, 680-689, 1975.

Schmidt, F.: Variable fine mesh in a spectral global model. Beit. Phys. Atmos., 50, 211-217, 1977.

Schuman, F. G.: Resuscitation of an integration procedure. NMC Office Note 54, 55 pp., 1971 [Available from NCEP/NOAA, 5200 Auth Road, Camp Springs, MD 20746.] Shapiro, R.: Smoothing, filtering and boundary effects. Rev. Geophys. Space Phys., 8, 359-387, 1970. 
Staniforth, A., and H. Mitchell: A variable resolution finite element technique for regional forecasting with primitive equations. Mon. Wea. Rev.,106, 439-447, 1978. Staniforth, A.N., and R. Daley: A baroclinic finite element model for regional forecasting with the primitive equations. Mon. Wea. Rev., 107, 107-121, 1979.

Staniforth, A.: Regional modeling: theoretical discussion, WMO PWPR Report Series, No. 7, WMO/TD-No. 699, 9-18, 1995.

Staniforth, A.: Regional modeling: A theoretical discussion. Meteorology and Atmospheric Physics, 63, 15-29, 1997.

Suarez, M. J., and L. L. Takacs: Documentation of the Aries/GEOS Dynamical Core Version 2, NASA Tech. Memo. 104606, NASA, Goddard Space Flight Center, Greenbelt, MD, 103 pp., 1995. [Available from Data Assimilation Office, NASA/GSFC, Greenbelt, MD20771.]

Sud, Y. C., and A. Molod: The roles of dry convection, cloud-radiation feedback processes and the influence of recent improvements in the parameterization of convection in the GLA GCM. Mon. Wea. Rev., 116, 2366-2387, 1988.

Takacs, L. L., A.Molod, and T. Wang: Goddard Earth Observing System(GEOS) General Circulation Model(GCM) Version 1. NASA Tech. Memo. 104606, v.1, NASA, Goddard Space Flight Center, Greenbelt ,MD, 97 pp., 1994 [Available from Data Assimilation Office, NASA/GSFC, Greenbelt, MD20771.]

Takacs, L. L., M.J. Suarez, W. Sawyer, and M.S. Fox-Rabinovitz: Filtering techniques on a stretched grid GCM. NASA Tech. Memo., 104606, v.15, 29 pp, 1999 [Available from Data Assimilation Office, NASA/GSFC, Greenbelt, MD20771.] 
Takle, E. S., and co-authors: Project to intercompare regional climate simulations (PIRCS): Description and initial results, J. Geophys. Res., 1999.

Vichnevetsky, R.: Wave propagation and reflection in irregular grids for hyperbolic equations. Appl. Numer. Math., North Holland, v. 2, No. 1-2, 133-166, 1987.

Xie, P. and P. A. Arkin, 1996: Analyses of global monthly precipitation using gauge observations, satellite estimates and numerical model predictions. J. Climate, 9, 840-858. Yessad, K, and P.Benard: Introduction of local mapping factor in the spectral part of the Meteo-France global variable mesh numerical forecast model. Quart. J. Roy. Meteor. Soc., 122, 1701-1719, 1996.

Zhou, J., Y.C. Sud, and K.-M. Lau: Impact of orographically induced gravity wave drag in the GLA GCM, Quart. J. Roy. Meteor. Soc., 122, 903-927, 1995.

\section{Figure captions}

Fig. 1a. A global stretched grid with: one area of interest over the U.S.

Fig. 1b. A global stretched grid with: multiple (four) areas of interest.

Fig. 2. The 1998 AMJ (April-May-June) $500 \mathrm{hPa}$ kinetic energy spherical harmonic spectra for the SG-GCM (solid line), SG-DAS (dotted line), and ECMWF reanalyses (dashed line).

Fig. 3. The 1998 AMJ (April-May-June) zonal mean vertical distributions of zonal wind for the: (a) SG-GCM, (b) SG-DAS, and (c) ECMWF reanalyses. The contour interval is $5 \mathrm{~m} / \mathrm{s}$.

Fig. 4. The 1998 AMJ (April-May-June) 500 hPa global heights for the: (a) SG-GCM, (b) SG-DAS, and (c) bias or (a-b). The contour interval is $100 \mathrm{~m}$ for (a) and (b), and $20 \mathrm{~m}$ for (c). 
Fig. 5. The 1998 AMJ (April-May-June) $850 \mathrm{hPa}$ global zonal winds for the:

(a) SG-GCM, (b) SG-DAS, and (c) ECMWF reanalysis. The contour interval is $2 \mathrm{~m} / \mathrm{s}$.

Fig. 6. The 1998 AMJ (April-May-June) precipitation for the U.S. region for the:

(a) SG-GCM, (b) SG-DAS, and (c) NCEP gauge data at 0.25 degree resolution available only over the U.S. The contour intervals are $2 \mathrm{~mm} /$ day.

Fig. 7. Same as in Fig. 6 but for the difference between the anomalous spring AMJ and close to normal winter JFM (January-February-March) 1998 precipitation. The contour intervals are $1 \mathrm{~mm} /$ day.

Fig. 8. The 1998 AMJ (April-May-June) 850 hPa zonal wind over the U.S. region for the: (a) SG-GCM, (b) SG-DAS, (c) ECMWF, and (d) bias or (a) - (b). The contour interval is $1 \mathrm{~m} / \mathrm{s}$.

Fig. 9. The 1998 AMJ (April-May-June) $850 \mathrm{hPa}$ zonal wind anomalies over the U.S. region for the: (a) SG-GCM, (b) SG-DAS, and (c) ECMWF. The contour interval is $1 \mathrm{~m} / \mathrm{s}$.

Fig. 10. The 1998 AMJ (April-May-June) temperature at 2 meters over the U.S. region for the: (a) SG-GCM, (b) SG-DAS, and (c) bias or (a) - (b). The contour intervals are $3^{\circ} \mathrm{K}$ for (a) and (b), and $1^{\circ} \mathrm{K}$ for (c).

Fig. 11. The 1998 MAM (March-April-May) precipitation over Mexico for the:

(a) SG-GCM, (b) SG-DAS, and (c) NCEP (Xie-Arkin) gauge data at 2 degree resolution. The contour interval is $2 \mathrm{~mm} /$ day.

Fig. 12. The 1998 MAM (March-April-May) precipitation anomalies over South America for the: (a) SG-GCM, (b) SG-DAS, and (c) NCEP (Xie-Arkin) gauge data at 2-degree resolution. The contour interval is $1 \mathrm{~mm} /$ day. 
Fig. 13. The 1998 July precipitation over China for the: (a) SG-GCM, (b) SG-DAS, and (c) NCEP (Xie-Arkin) gauge data at 2-degree resolution. The contour interval is $1 \mathrm{~mm} /$ day.

Fig. 14. The 1998 July precipitation anomalies over China for the: (a) SG-GCM, (b) SG-DAS, and (c) NCEP (Xie-Arkin) gauge data at 2 degree resolution. The contour intervals are $2 \mathrm{~mm} /$ day.

Fig. 15. The DJ (December 1997 and January 1998) precipitation anomalies over Australia for the: (a) SG-GCM, (b) SG-DAS, and (c) NCEP (Xie-Arkin) gauge data at 2-degree resolution. The contour interval is $1 \mathrm{~mm} /$ day.

Fig. 16. The 1998 AMJJASON (April through November) precipitation anomalies over Australia for the: (a) SG-GCM, (b) SG-DAS, and (c) NCEP (Xie-Arkin) gauge data at 2 -degree resolution. The contour interval is $1 \mathrm{~mm} /$ day.

Fig. 17. The 1998 JJAS (June to September) precipitation over the Indian region for the: (a) SG-GCM, (b) SG-DAS, and (c) NCEP (Xie-Arkin) gauge data at 2-degree resolution. The contour interval is $2 \mathrm{~mm}$ /day.

Fig. 18. The 1998 JJAS (June to September) precipitation over the African Sahel region and its vicinity for the: (a) SG-GCM, (b) SG-DAS, and (c) NCEP (Xie-Arkin) gauge data at 2 -degree resolution. The contour interval is $2 \mathrm{~mm} /$ day. 


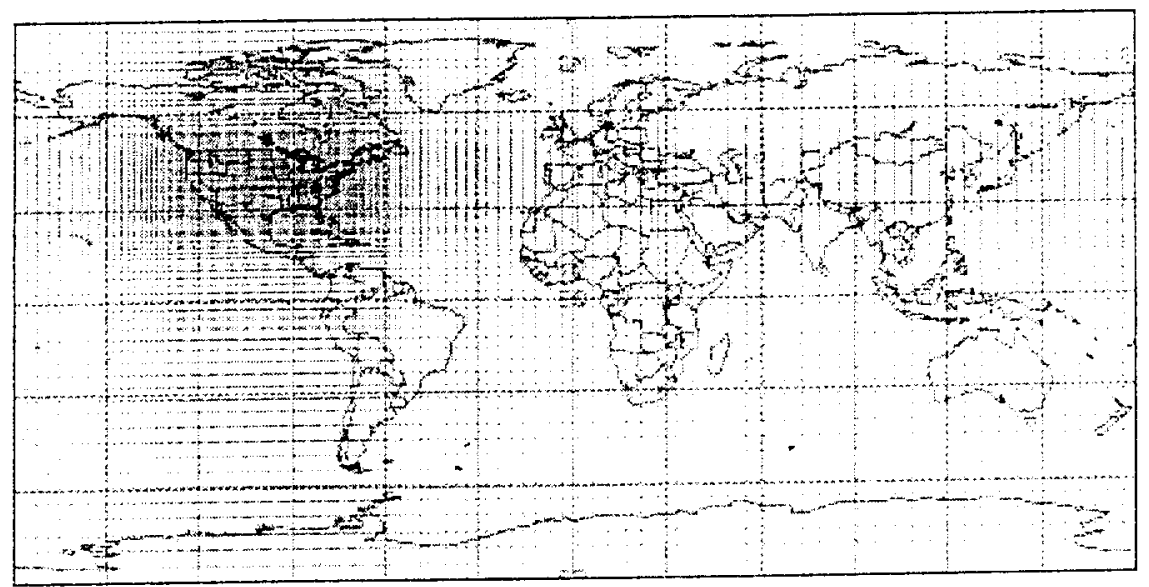

Fig. 1a. A global stretched grid with: one area of interest over the U.S. 


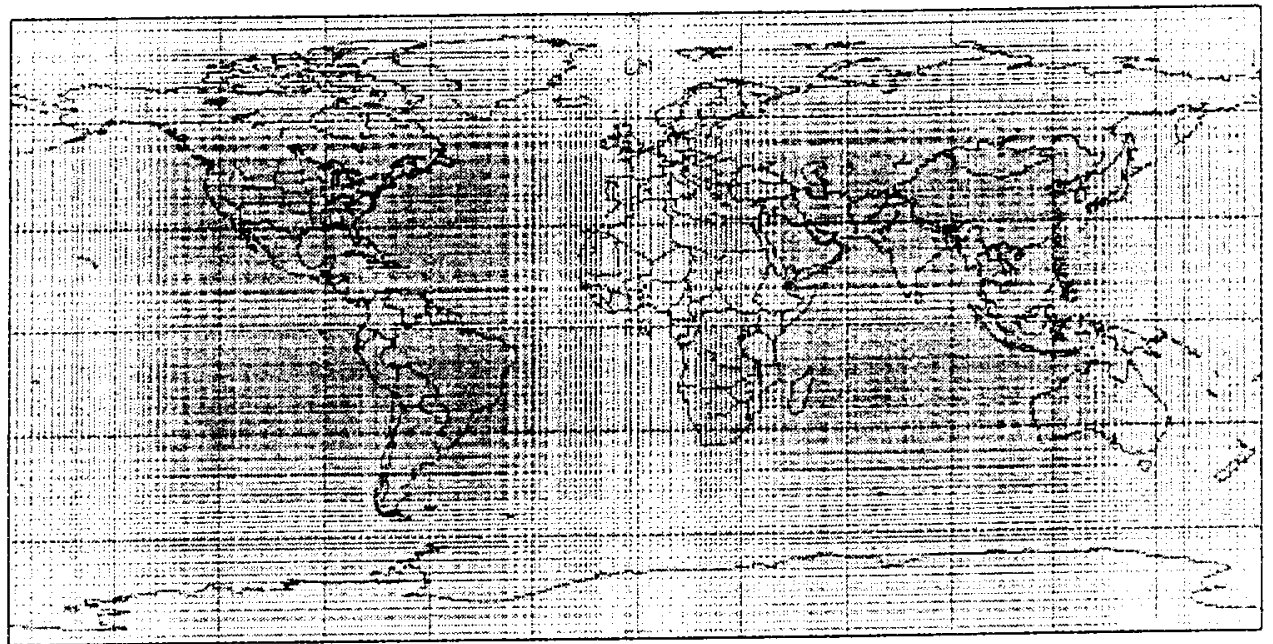

Fig. 1b. A global stretched grid with multiple (four) areas of interest. 


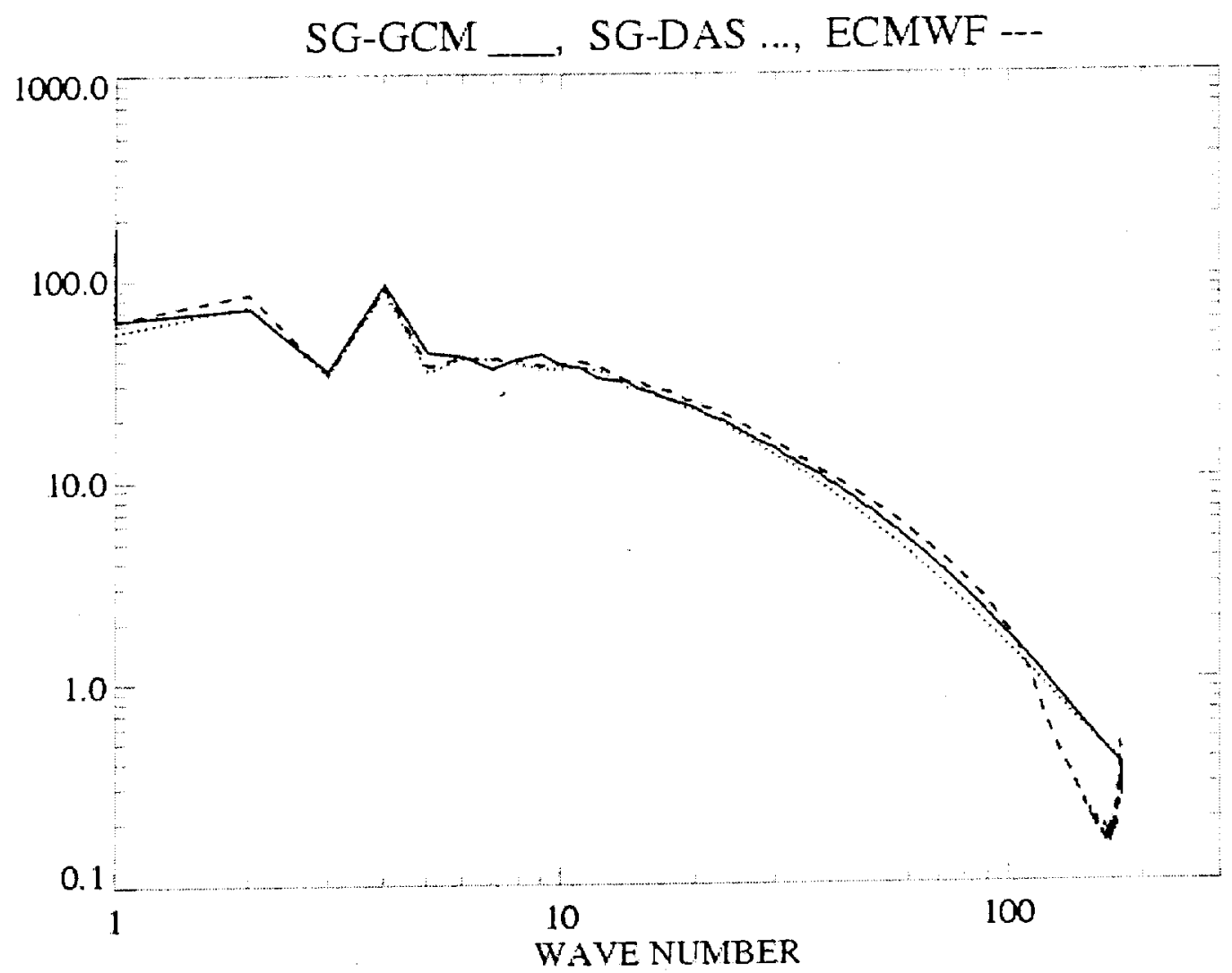

Fig. 2. The 1998 AMJ (April-May-June) $500 \mathrm{hPa}$ kinetic energy spherical harmonic spectra for the SG-GCM (solid line), SG-DAS (dotted line), and ECMWF reanalyses (dashed line). 
(c) SG-GCM(5OKM) AMJ $1998 \mathrm{U}$-wind

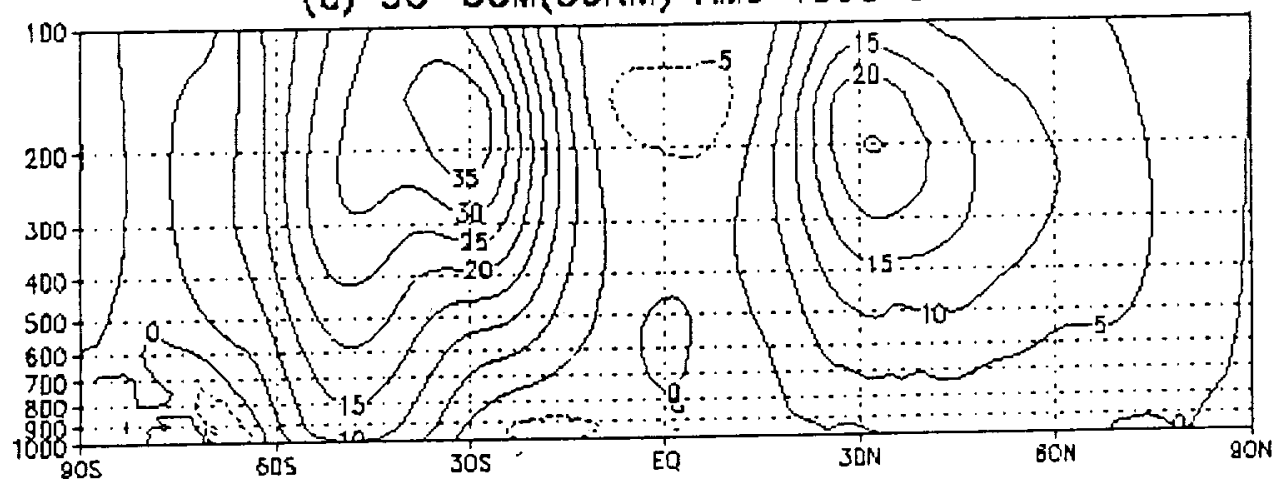

(b) SG-DAS (5OKM) AMJ $1998 \mathrm{U}$-wind

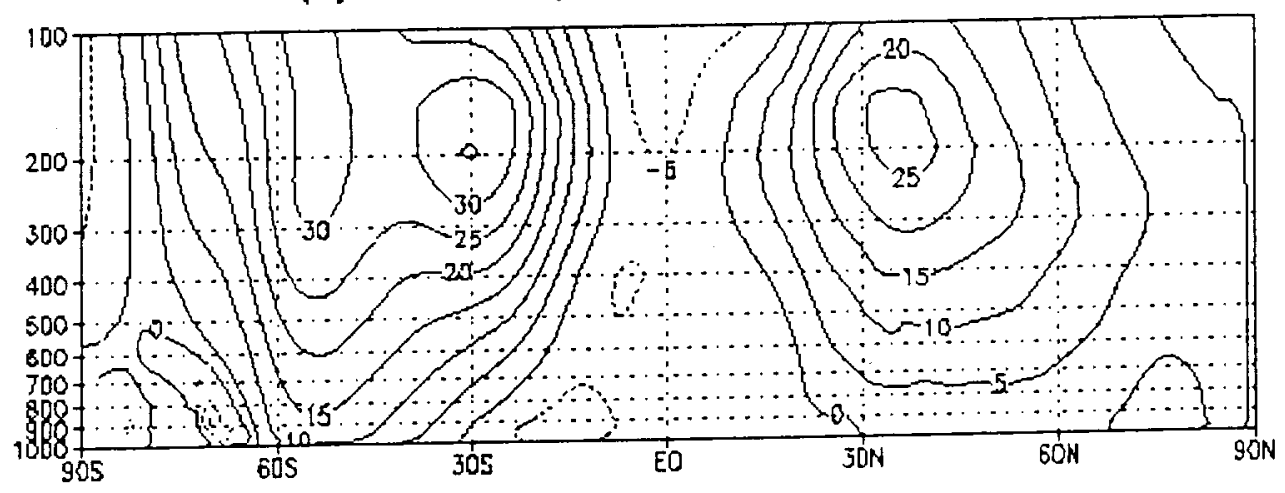

(c) ECMWF AMJ $1998 \mathrm{U}$-wind

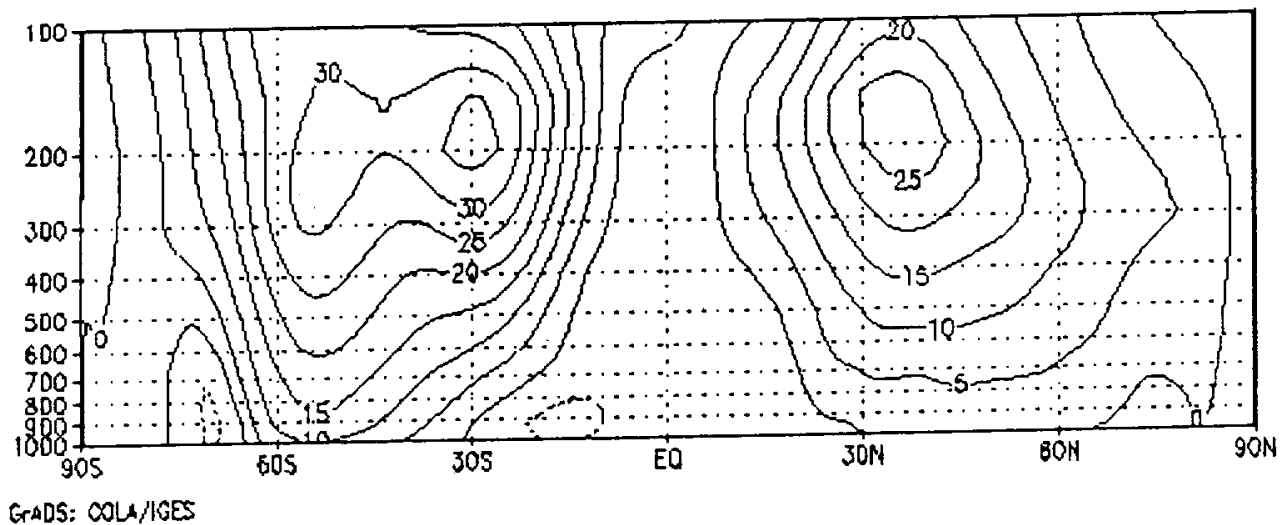

Fig. 3. The 1998 AMJ (April-May-June) zonal mean vertical distributions of zonal wind for the: (a) SG-GCM, (b) SG-DAS, and (c) ECMWF reanalyses. The contour interval is $5 \mathrm{~m} / \mathrm{s}$. 
(c) SG-GCM(50km) AM $1998 \mathrm{H}-500$

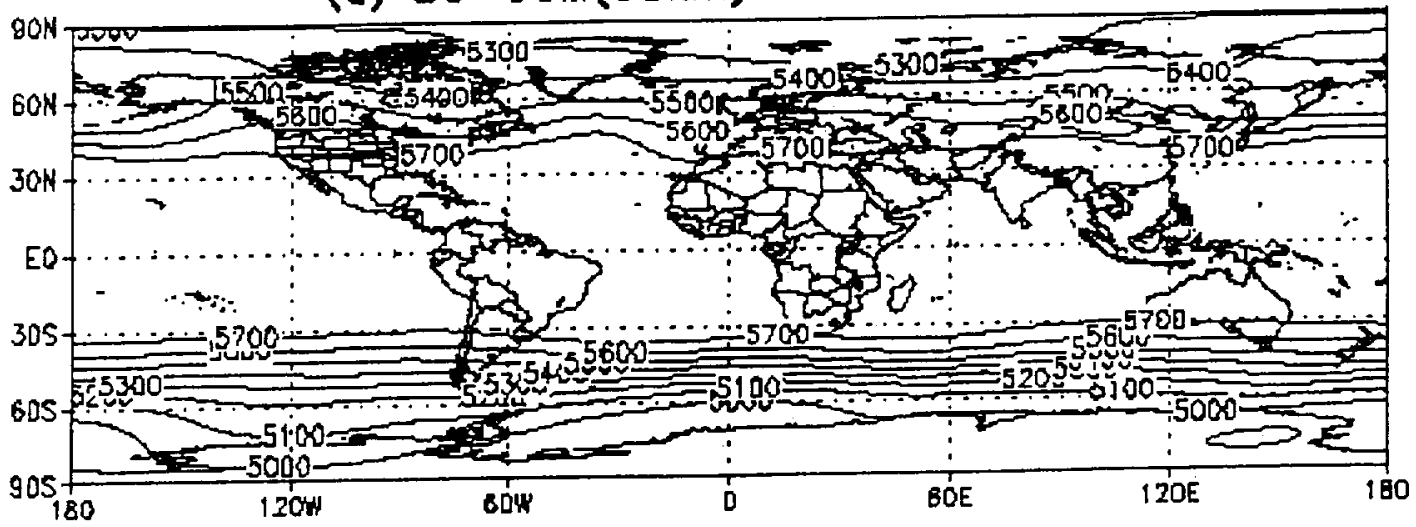

(b) SG-DAS(SOKM) AMJ $1998 \mathrm{H}-500$

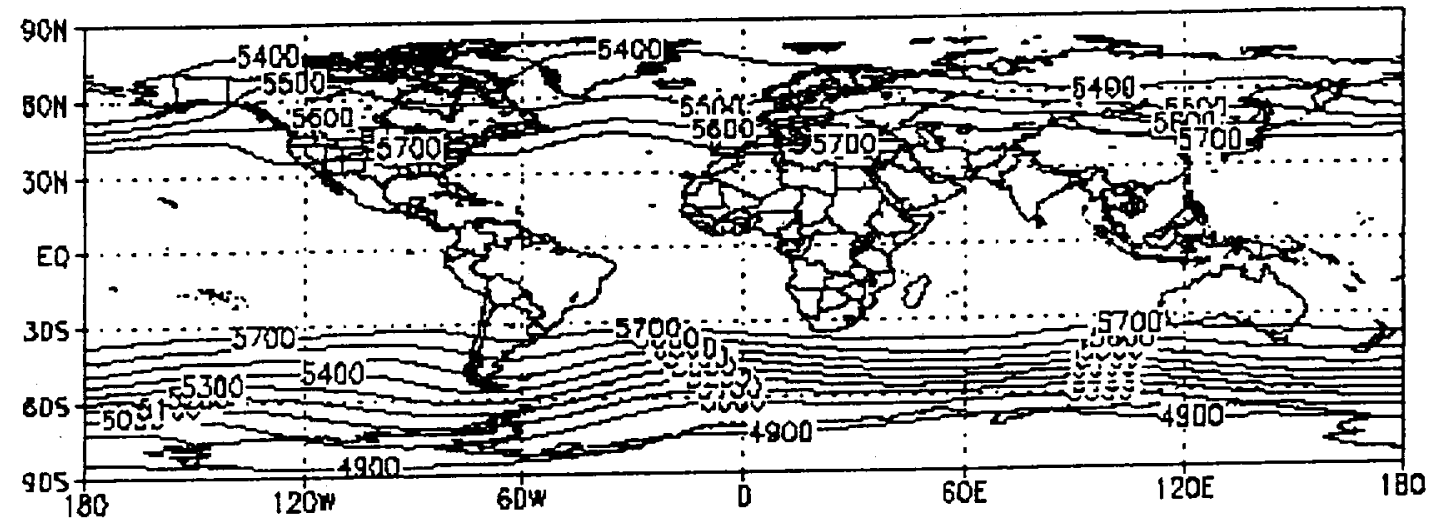

\section{(c) $(a-b)$ AM」 $1998 \mathrm{H}-500$}

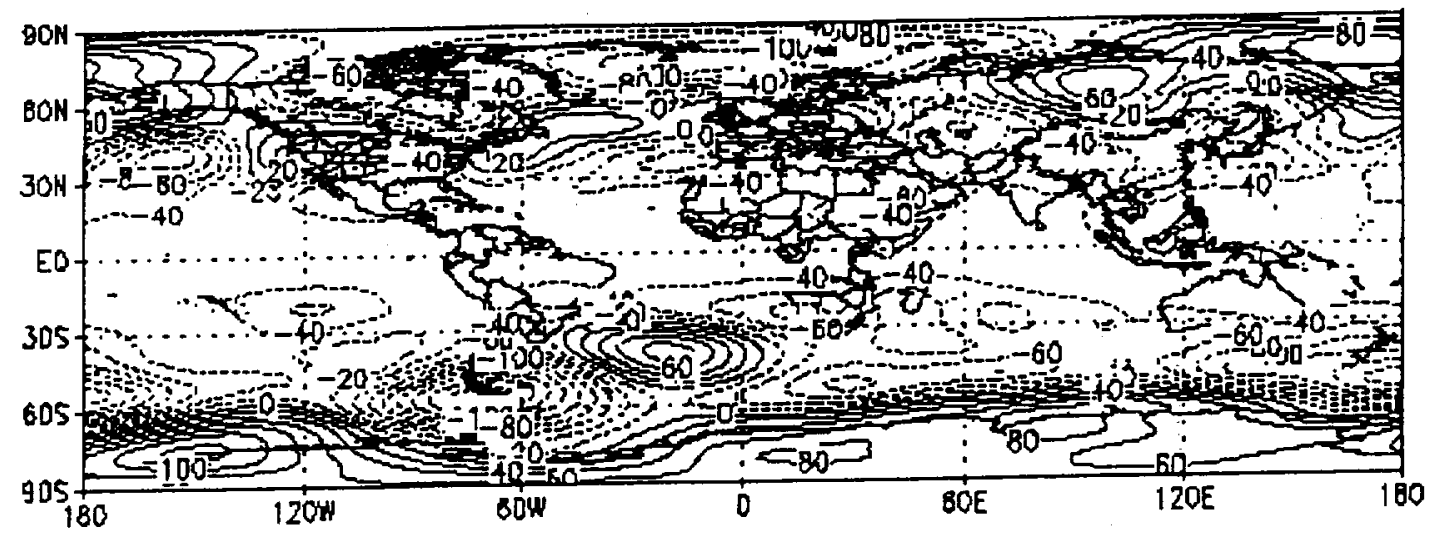

Fig. 4. The 1998 AMJ (April-May-June) $500 \mathrm{hPa}$ global heights for the: (a) SG-GCM, (b) SG-DAS, and (c) bias or (a-b). The contour interval is $100 \mathrm{~m}$ for (a) and (b), and $20 \mathrm{~m}$ for (c). 
(a) SG-GCM(50km) AMJ 1998 U-850

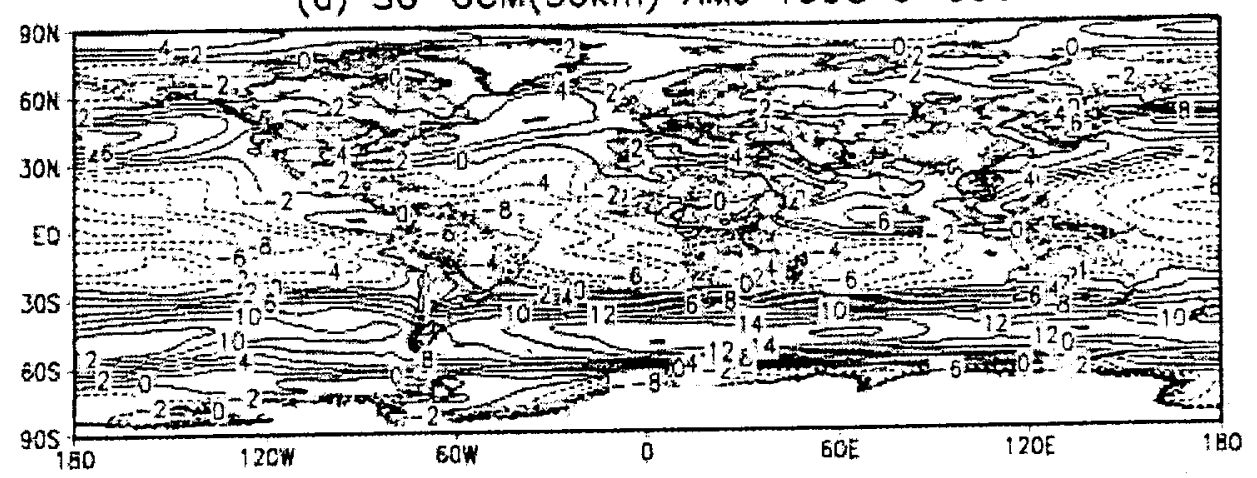

(b) SG-DAS(50km) AMJ $1998 \mathrm{U}-850$

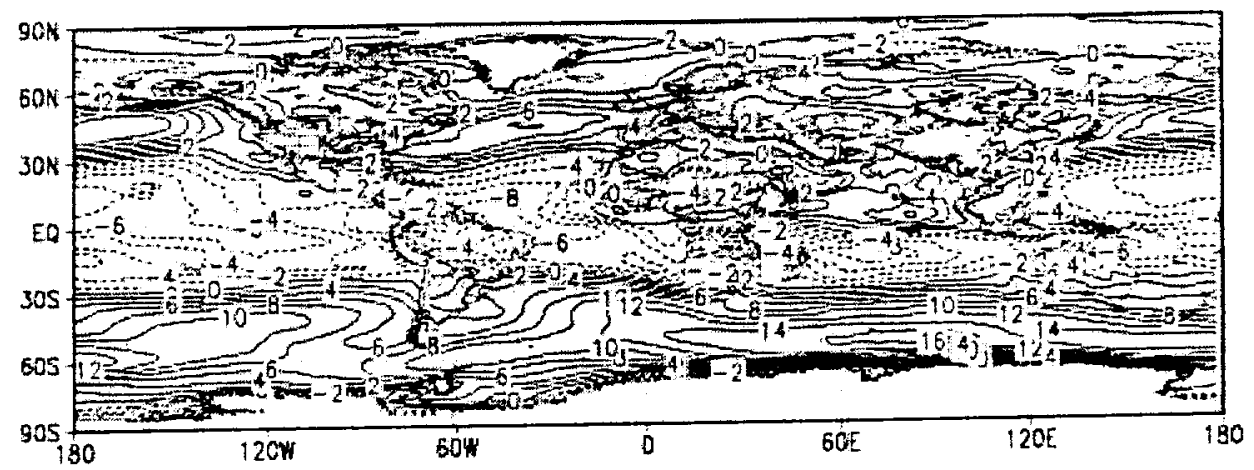

(c) ECMWF (1×1) AMJ $1998 \quad U-850$

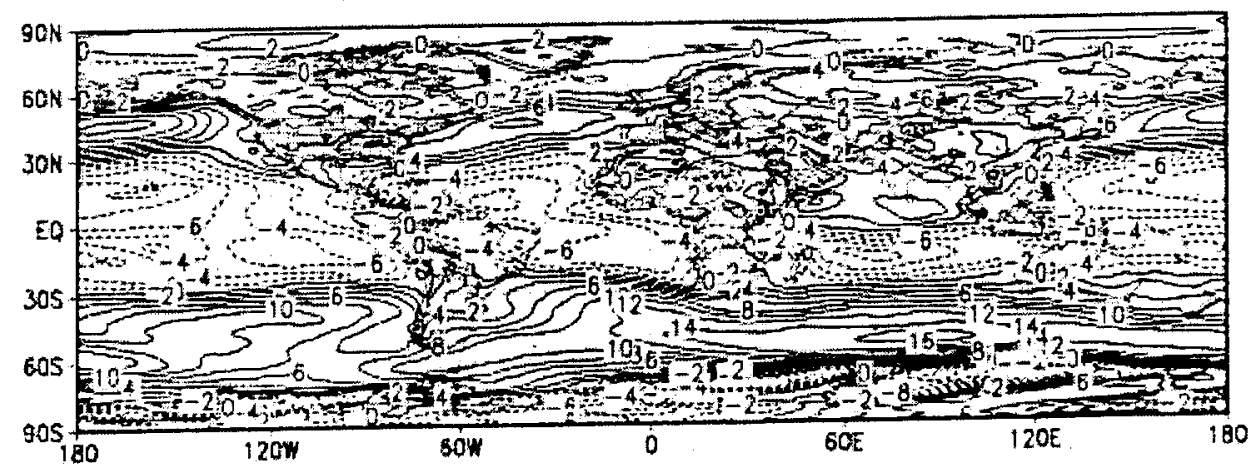

Fig. 5. The 1998 AMJ (April-May-June) $850 \mathrm{hPa}$ global zonal winds for the:

(a) SG-GCM, (b) SG-DAS, and (c) ECMWF reanalysis. The contour interval is $2 \mathrm{~m} / \mathrm{s}$. 
(o) SG-GCM(50km) AMJ 1998 PRECIP

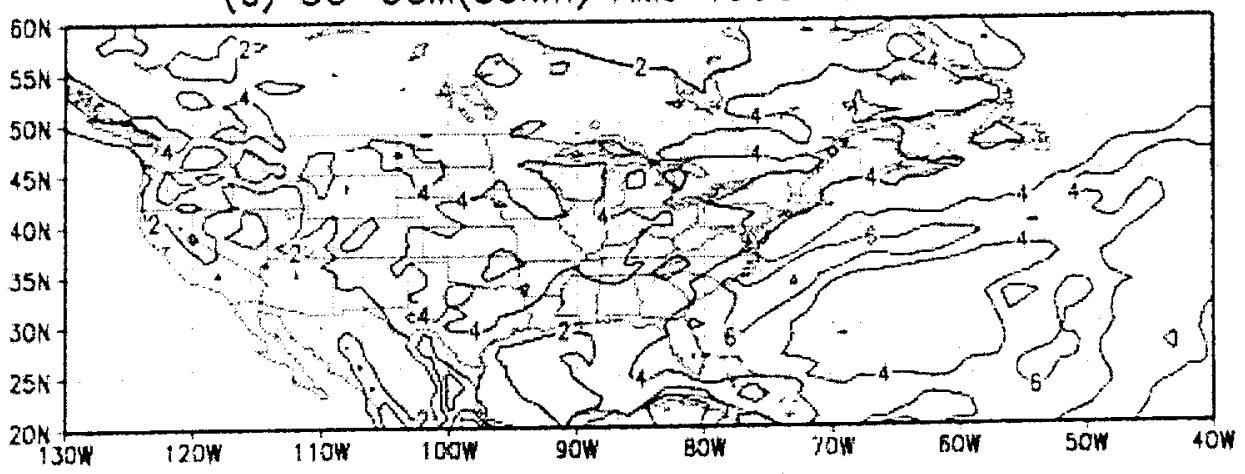

(b) SG-DAS(50KM) AMJ 1998 PRECIP

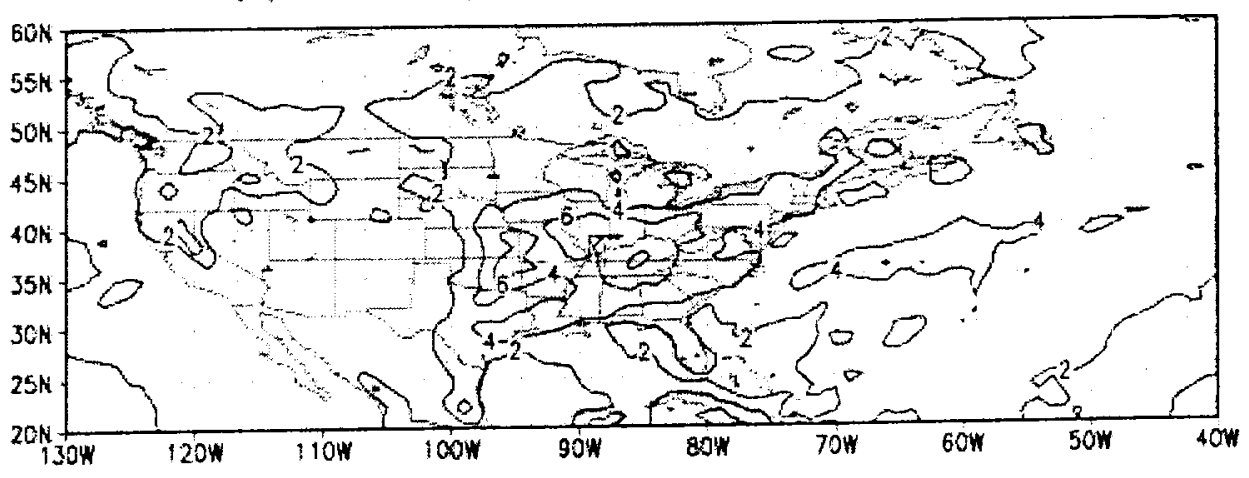

(c) NCEP GAUGE(.25x.25) AMJ 1998 PRECIP

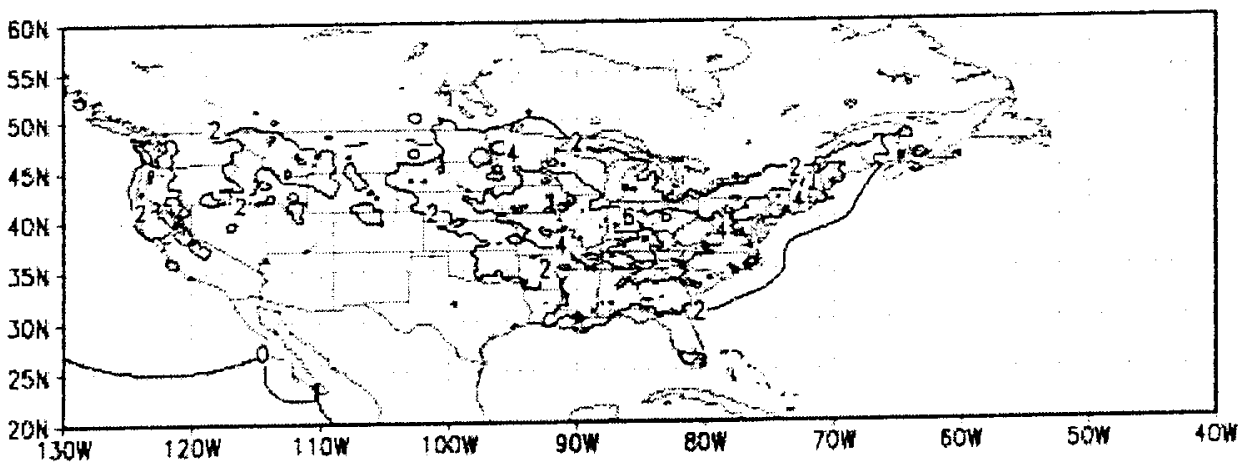

Fig. 6. The 1998 AMJ (April-May-June) precipitation for the U.S. region for the:

(a) SG-GCM, (b) SG-DAS, and (c) NCEP gauge data at 0.25 degree resolution available only over the U.S. The contour intervals are $2 \mathrm{~mm} /$ day. 


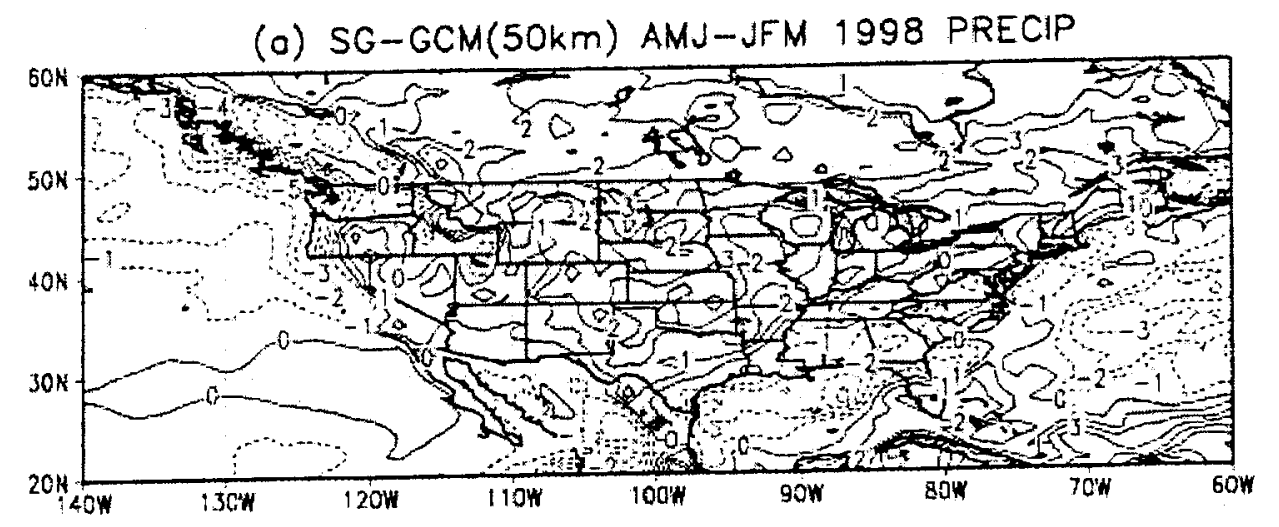

(b) SG-DAS(50KM) AMJ-JFM 1998 PRECIP

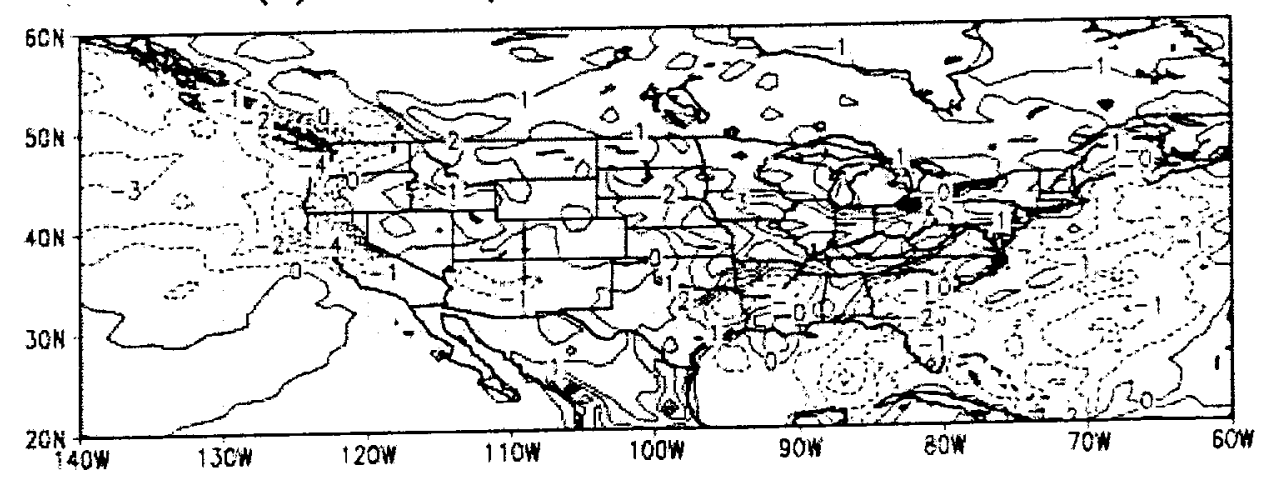

(c) NCEP GAUGE(0.25 $\times 0.25)$ AMJ-JFM 1998 PRECIP

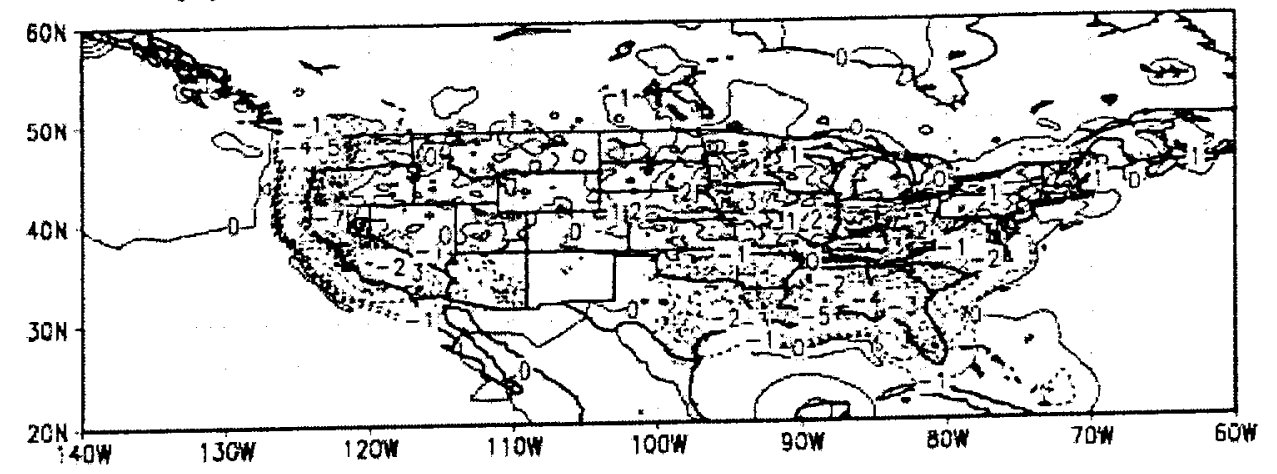

Fig. 7. Same as in Fig. 6 but for the difference between the anomalous spring AMJ and close to normal winter JFM (January-February-March) 1998 precipitation. The contour intervals are $1 \mathrm{~mm} /$ day. 
(a) $5 G-6 C M(50 \mathrm{~km})$ ANu $1998 \mathrm{U}-850$

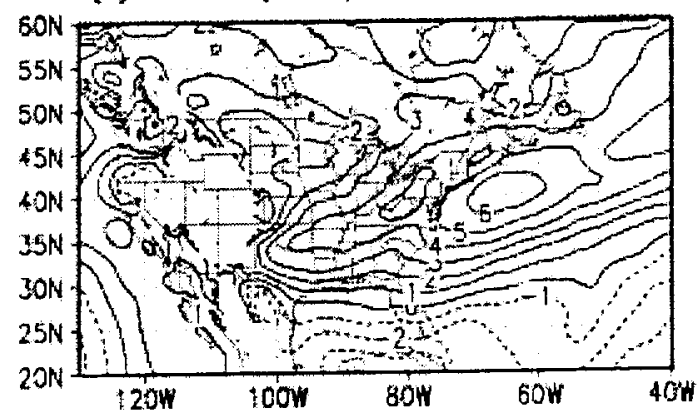

(b) SG-DAS(5OKM) AMJ 1898 U-850

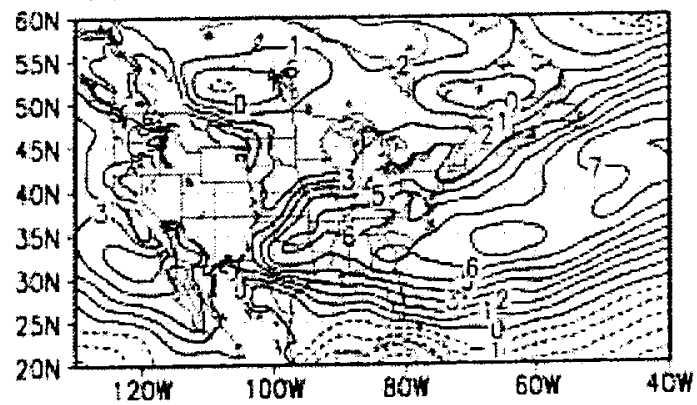

(c) ECWWF (ixi) AUJ 1998 U-850

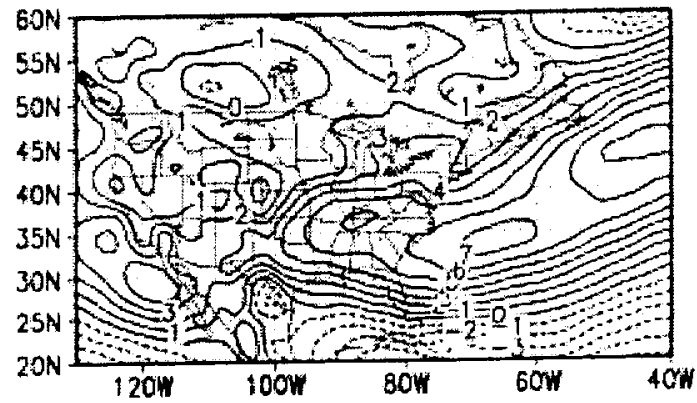

(d) $a-b$ ans 1998 U-850

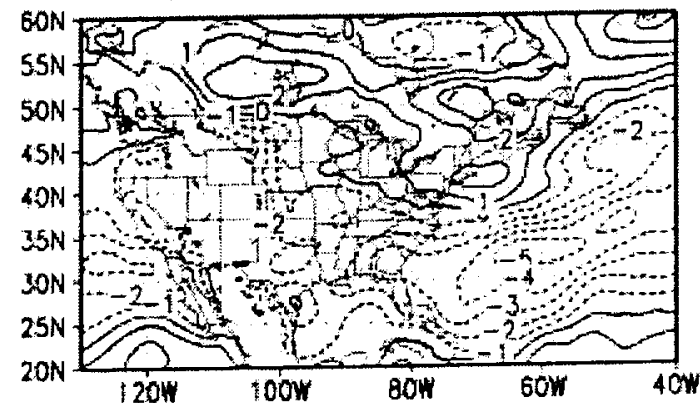

Fig. 8. The 1998 AMJ (April-May-June) $850 \mathrm{hPa}$ zonal wind over the U.S. region for the: (a) SG-GCM, (b) SG-DAS, (c) ECMWF, and (d) bias or (a) - (b). The contour interval is $1 \mathrm{~m} / \mathrm{s}$. 
(a) SG-GCM(50km) ANOMALY AMJ $1998 \mathrm{U}-850$

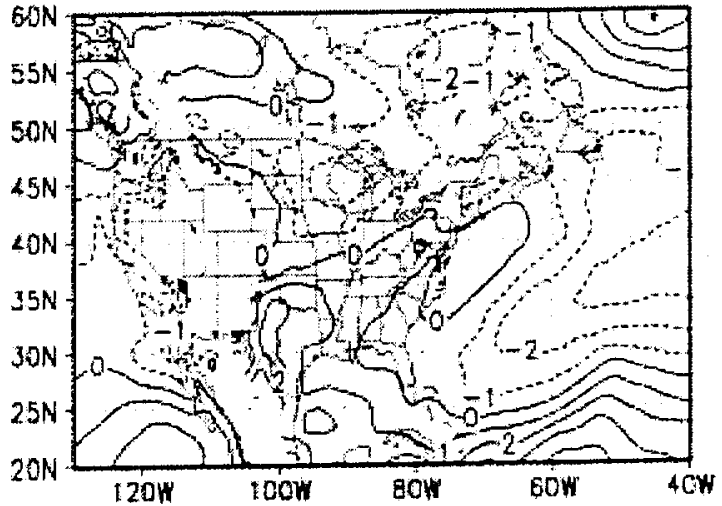

(b) SG-DAS(5OKM) ANOMALY AMJ $1998 \mathrm{U}-850$

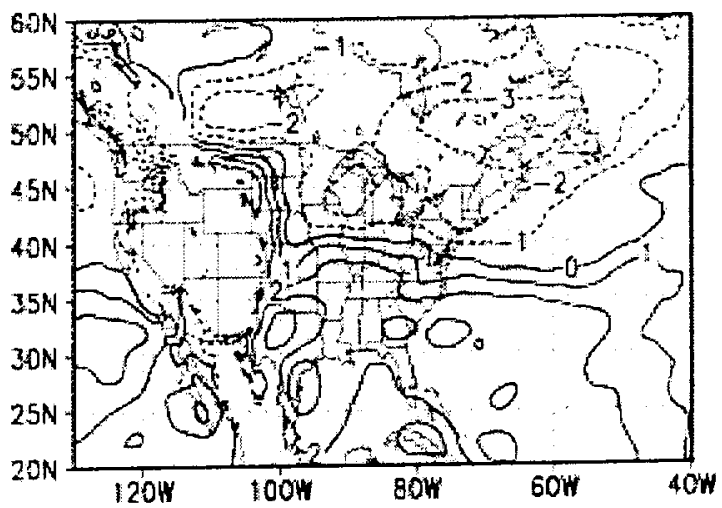

(c) ECWWF (ix1) ANOWALY AMJ 1998 U-850

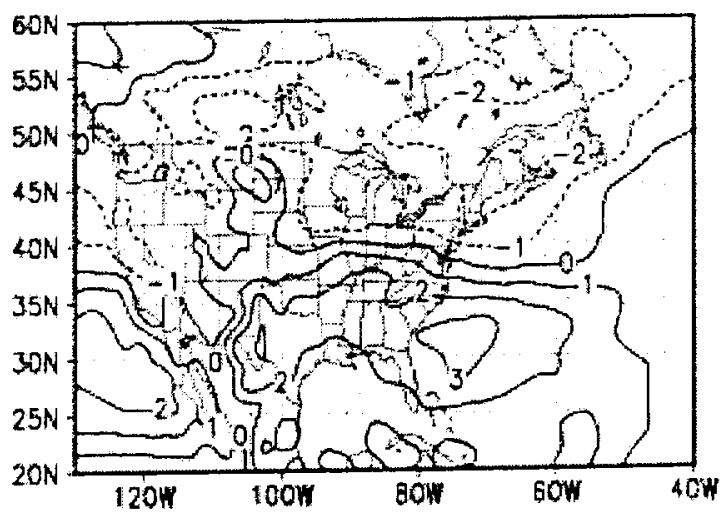

Fig. 9. The 1998 AMJ (April-May-June) $850 \mathrm{hPa}$ zonal wind anomalies over the U.S. region for the: (a) SG-GCM, (b) SG-DAS, and (c) ECMWF. The contour interval is $1 \mathrm{~m} / \mathrm{s}$. 
(o) $5 G-G C M(50 \mathrm{~km})$ AMJ $1998 \mathrm{~T} 2 \mathrm{M}$

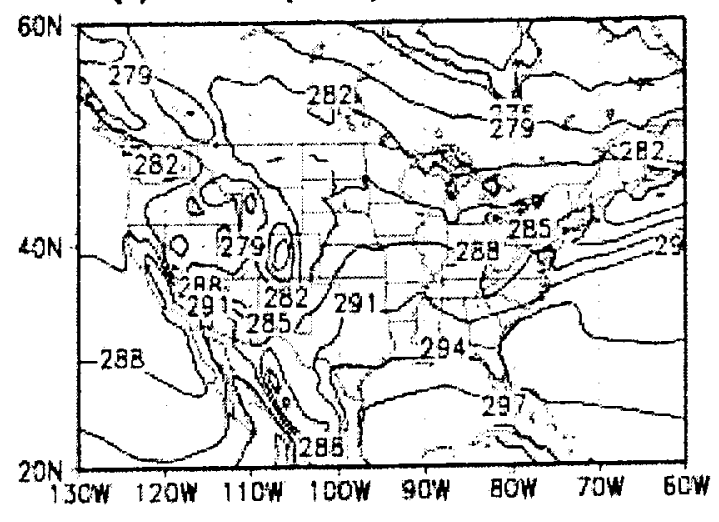

(b) SG-DAS(5OKM) ANJ 1998 T2M

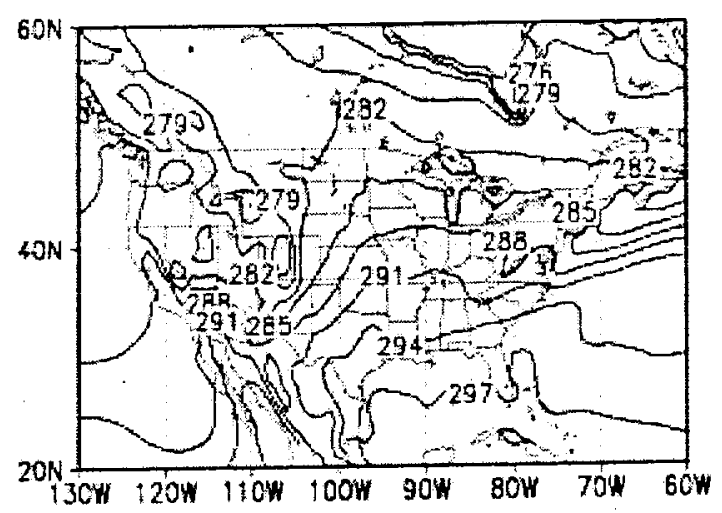

(c) (o-b) ANS $1998 \mathrm{~T} 2 \mathrm{~N}$

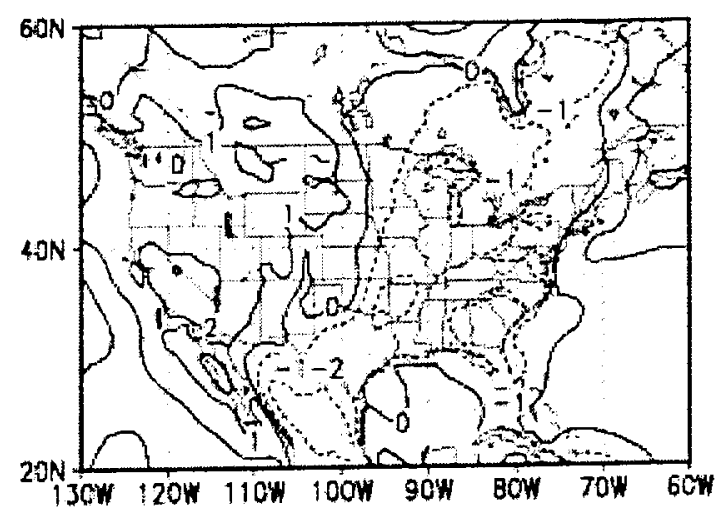

Fig. 10. The 1998 AMJ (April-May-June) temperature at 2 meters over the U.S. region for the: (a) SG-GCM, (b) SG-DAS, and (c) bias or (a) - (b). The contour intervals are $3^{\circ} \mathrm{K}$ for (a) and (b), and $1^{\circ} \mathrm{K}$ for (c). 
(o) SG-GCM(50km) MAM 1998 PRECIP

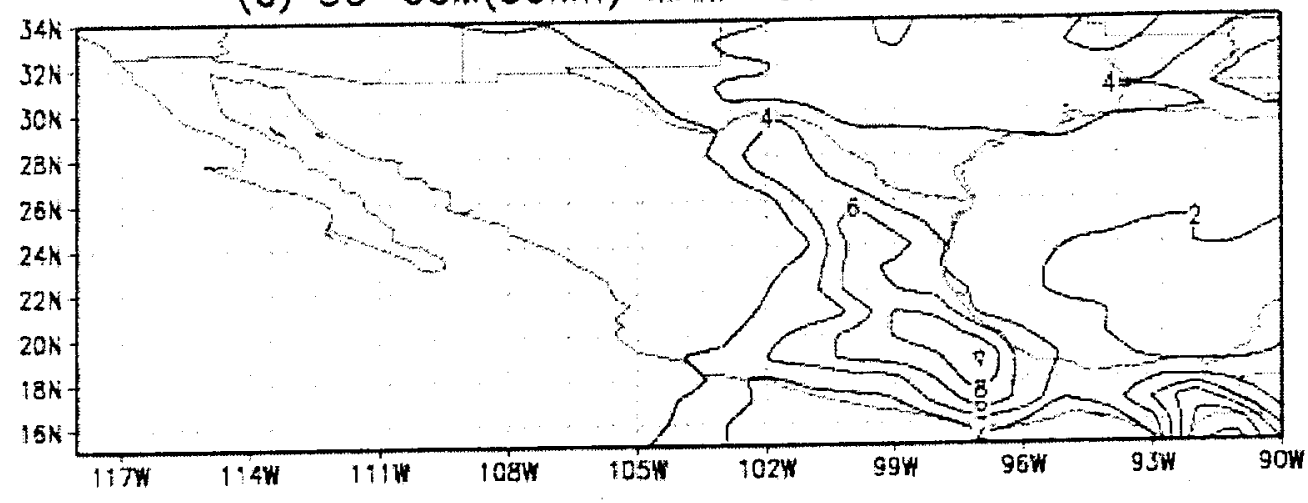

(b) SG-DAS(5OKM) MAM 1998 PRECIP

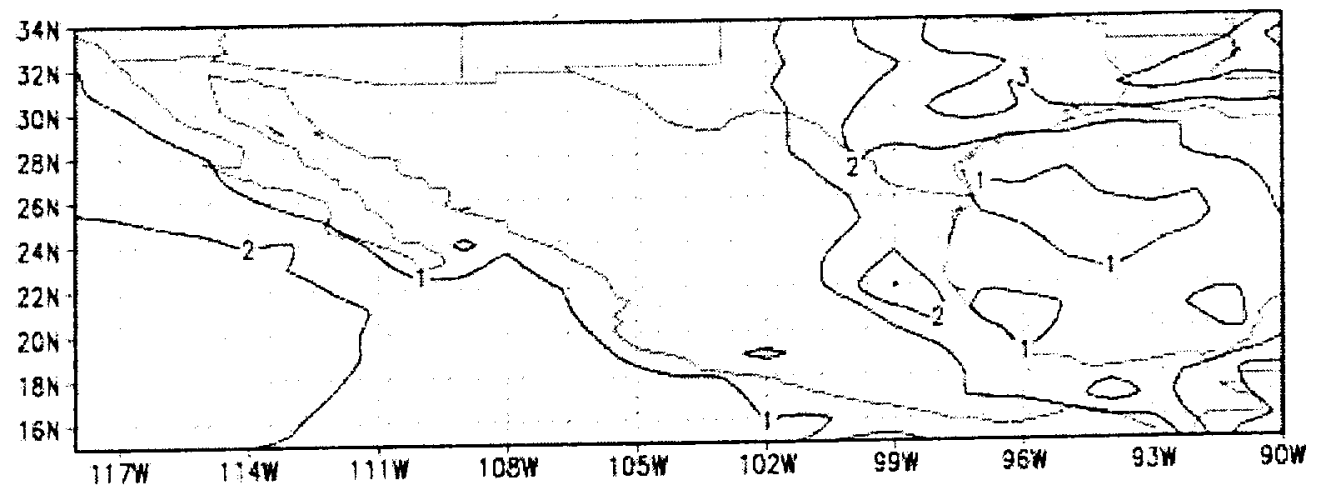

(c) NCEP(Xie-Arkin) MAM 1998 PRECIP

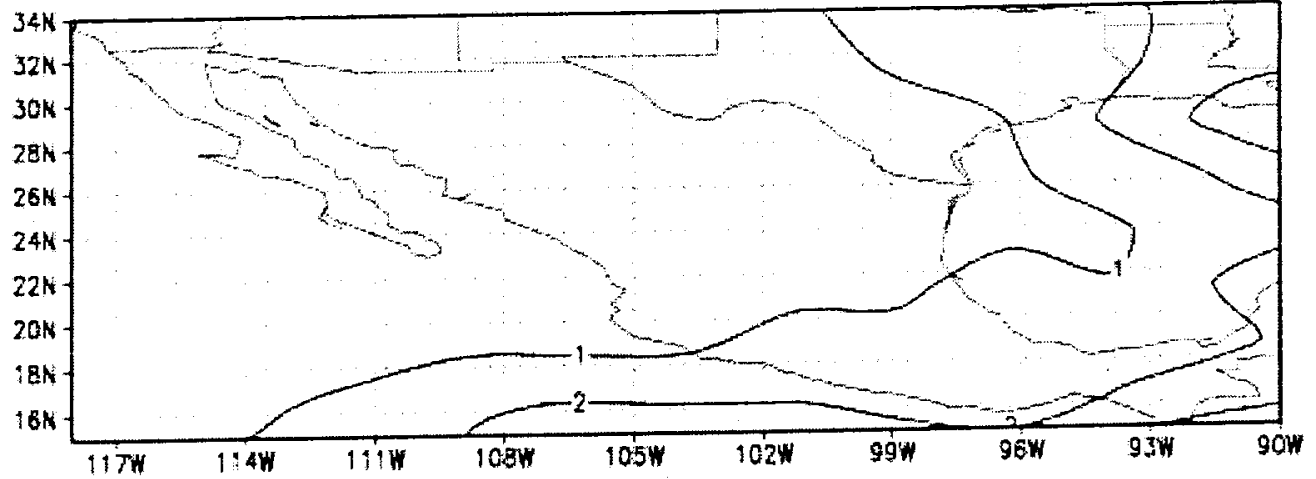

Fig. 11. The 1998 MAM (March-April-May) precipitation over Mexico for the: (a) SG-GCM, (b) SG-DAS, and (c) NCEP (Xie-Arkin) gauge data at 2 degree resolution. The contour interval is $2 \mathrm{~mm} /$ day. 


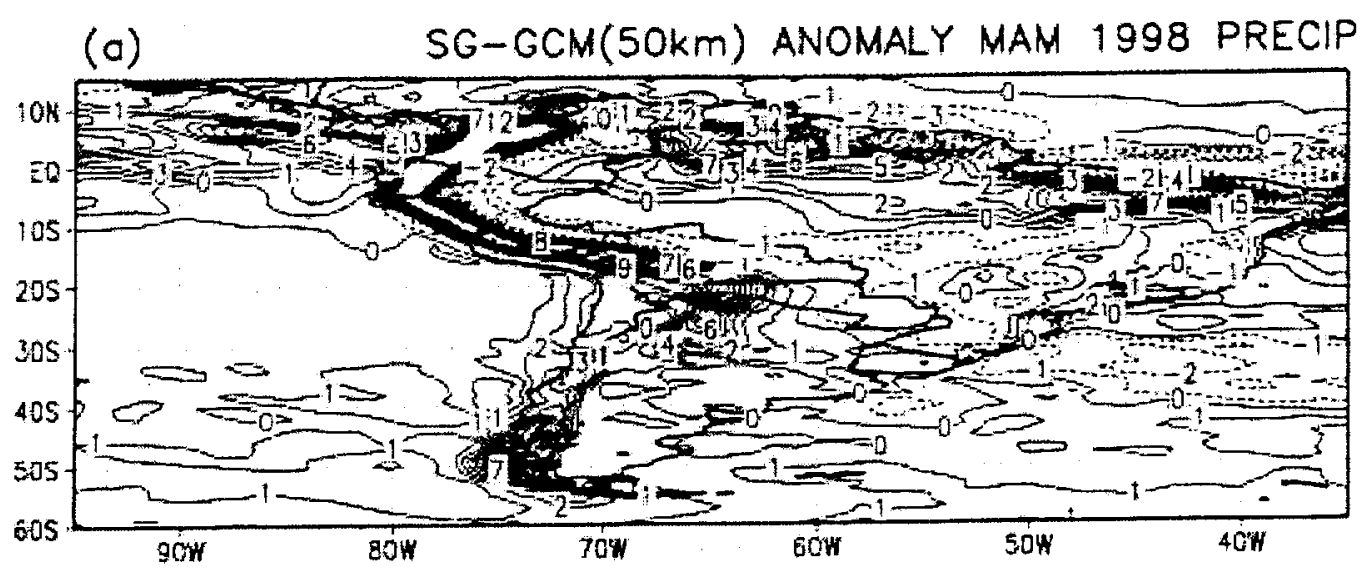

(b)

$$
\text { SG-DAST(5OKM) ANOMALY MAM } 1998 \text { PRECIP }
$$

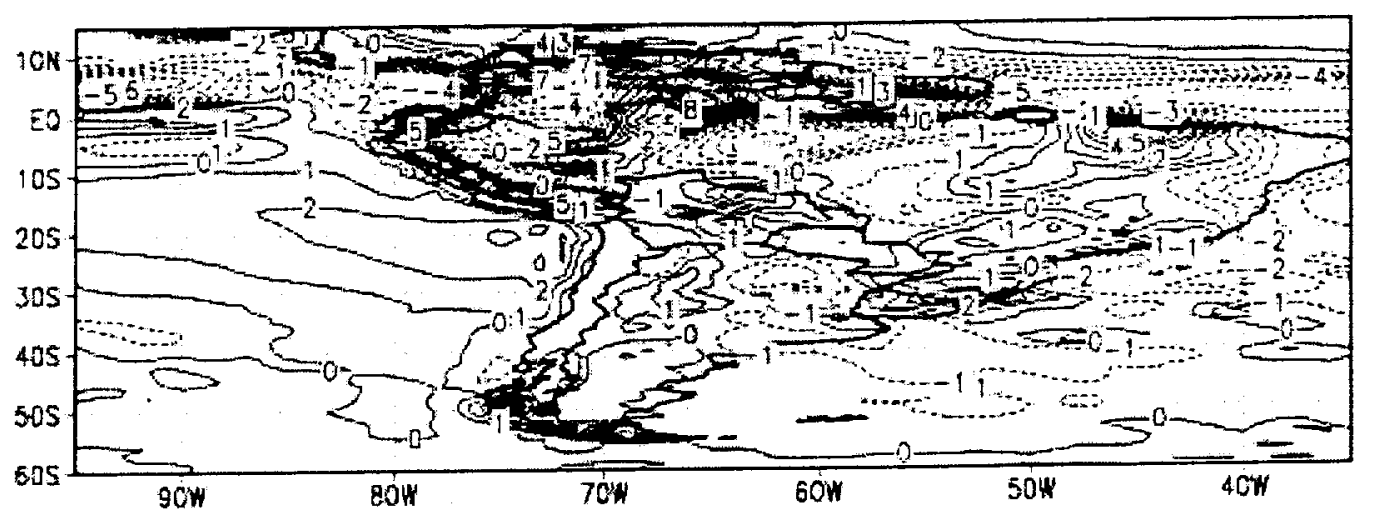

(c) XIE-ARKIN GAUGE ANOMALY MAM 1998 PRECIP

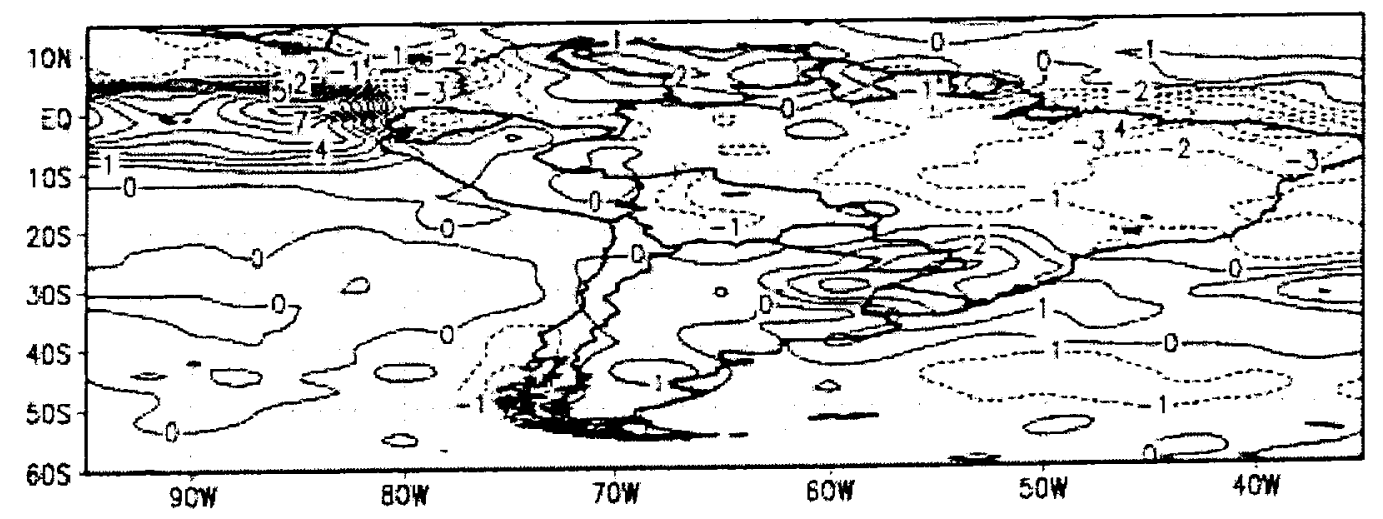

Fig. 12. The 1998 MAM (March-April-May) precipitation anomalies over South America for the: (a) SG-GCM, (b) SG-DAS, and (c) NCEP (Xie-Arkin) gauge data at 2-degree resolution. The contour interval is $1 \mathrm{~mm} /$ day. 
(a) SG-GCM $(50 \mathrm{~km})$ JULY 1998 PRECIP

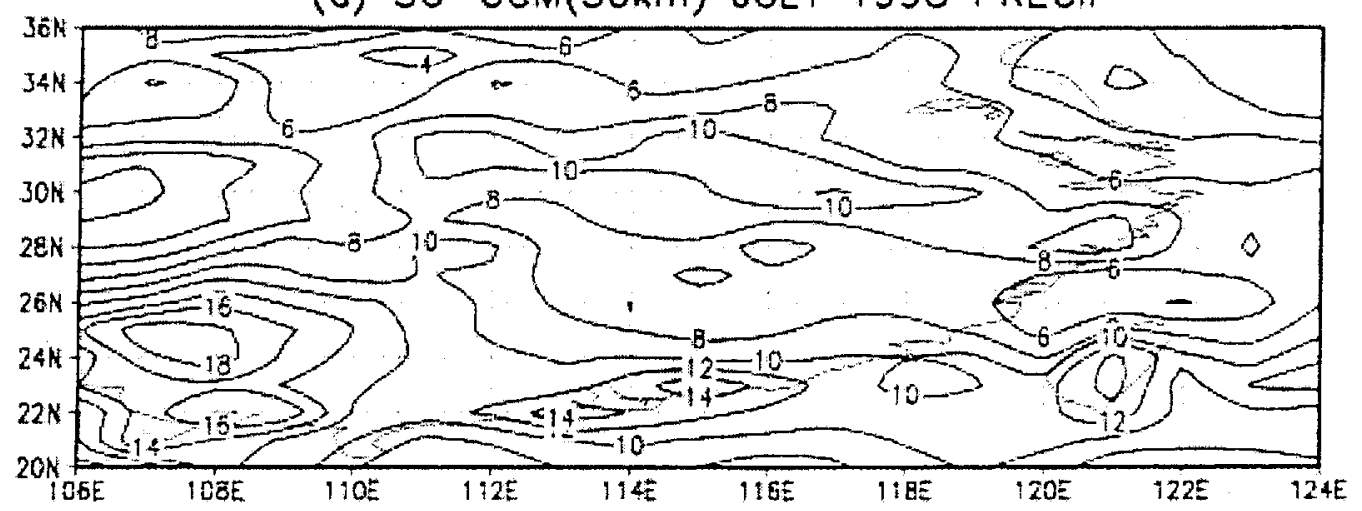

(b) SG-DAS(5OKM) JULY 1998 PRECIP

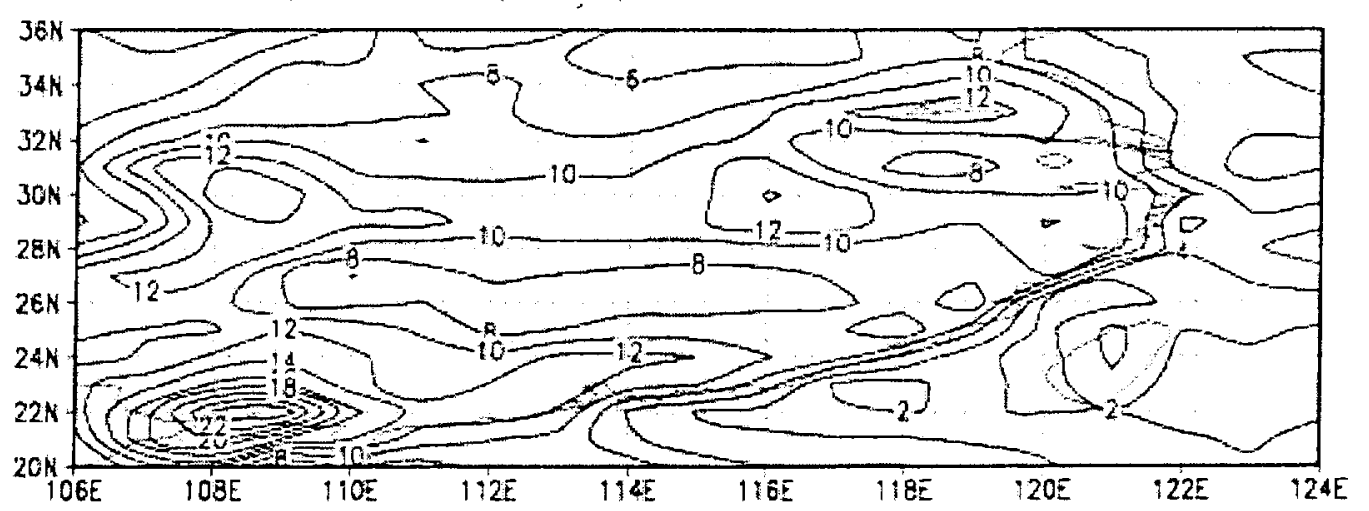

(c) NCEP(Xie-Arkin) JULY 1998 PRECIP

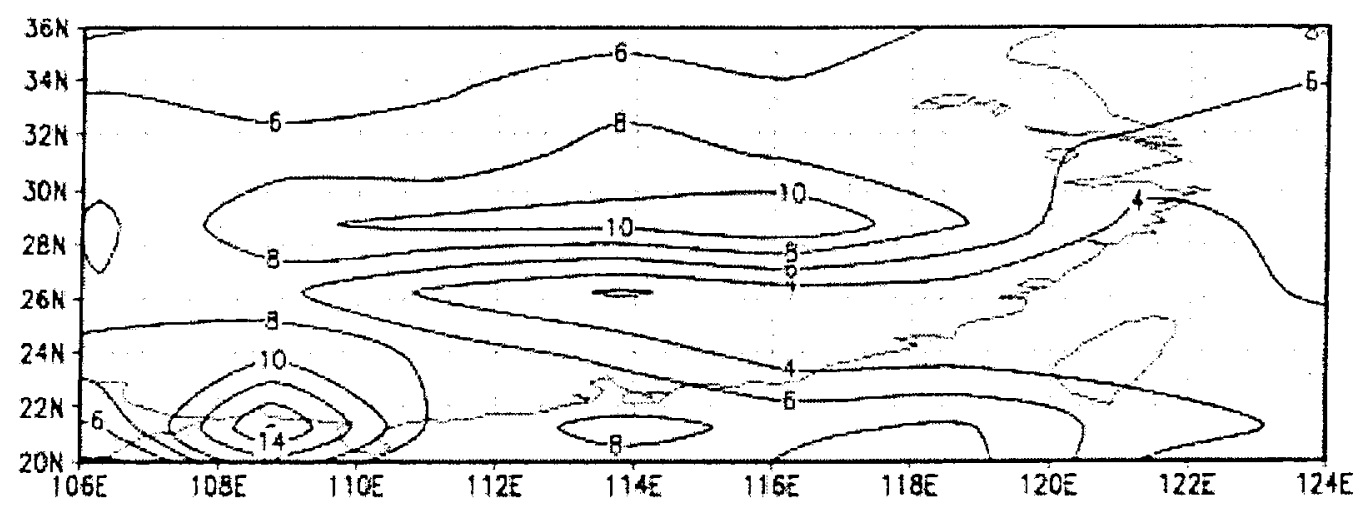

Fig. 13. The 1998 July precipitation over China for the: (a) SG-GCM, (b) SG-DAS, and (c) NCEP (Xie-Arkin) gauge data at 2-degree resolution. The contour interval is $1 \mathrm{~mm} /$ day. 
(a) SG-GCM(5OKM) ANOMALY JULY 1998 PRECIP

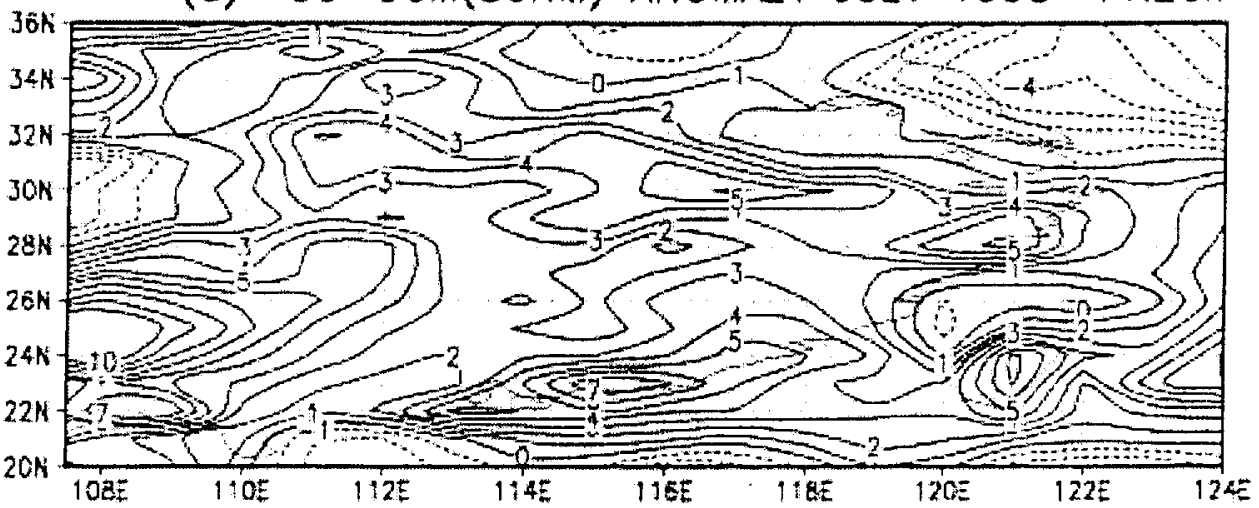

(b) SG-GCM(5OKM) ANOMALY JULY 1998 PRECIP

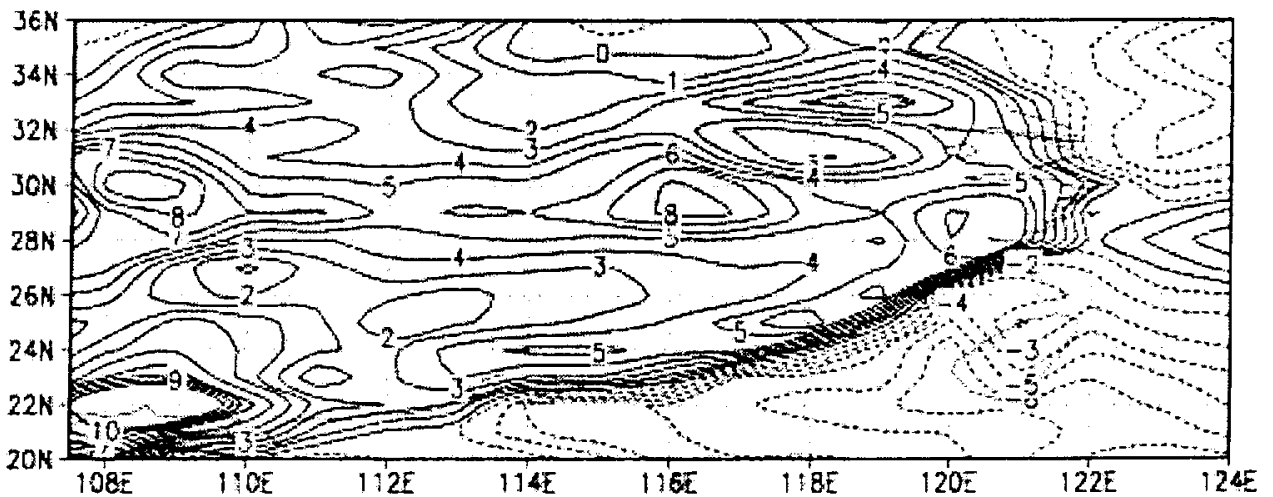

(c) NCEP(Xie-Arkin) ANOMALY JULY 1998 PRECIP

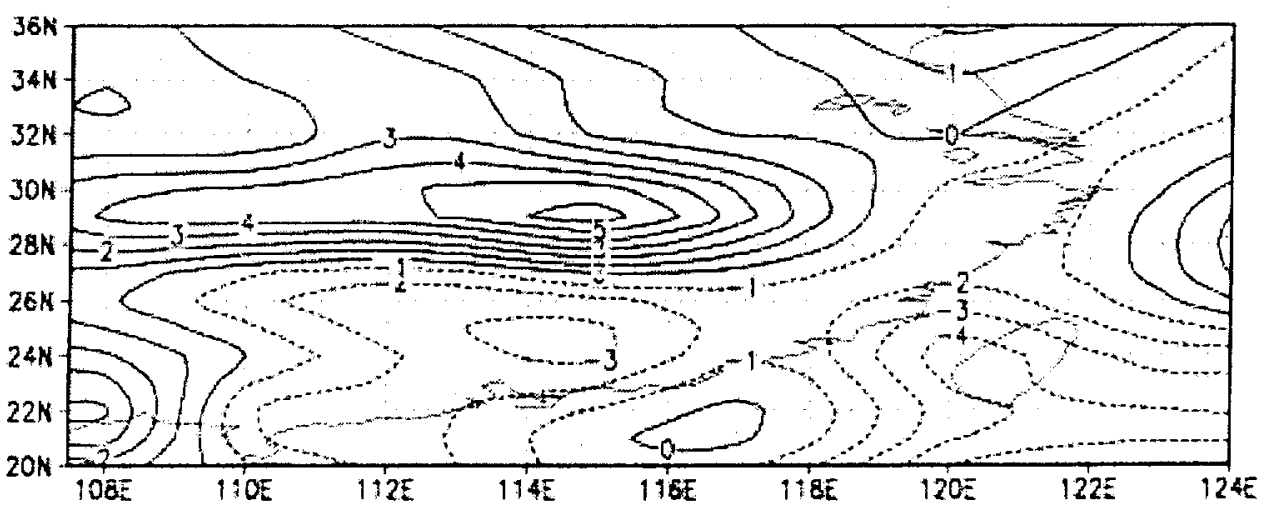

Fig. 14. The 1998 July precipitation anomalies over China for the: (a) SG-GCM, (b) SG-DAS, and (c) NCEP (Xie-Arkin) gauge data at 2 degree resolution. The contour intervals are $2 \mathrm{~mm} /$ day. 


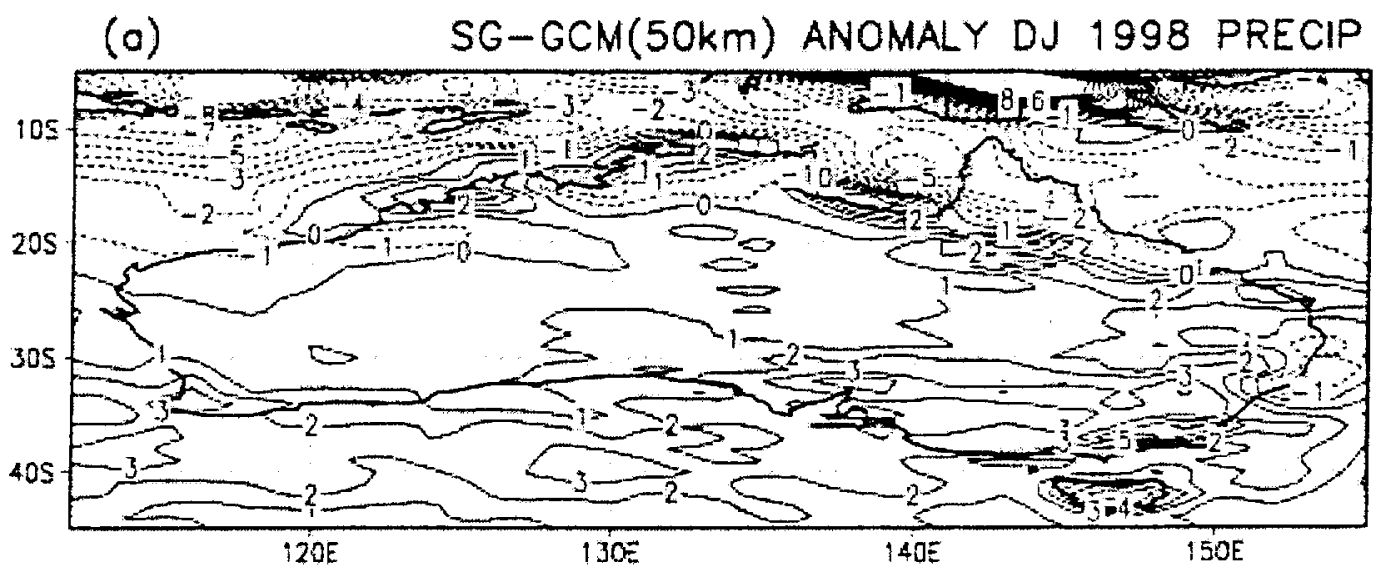

(b) SG-DAS(5OKM) ANOMALY DJ 1998 PRECIP

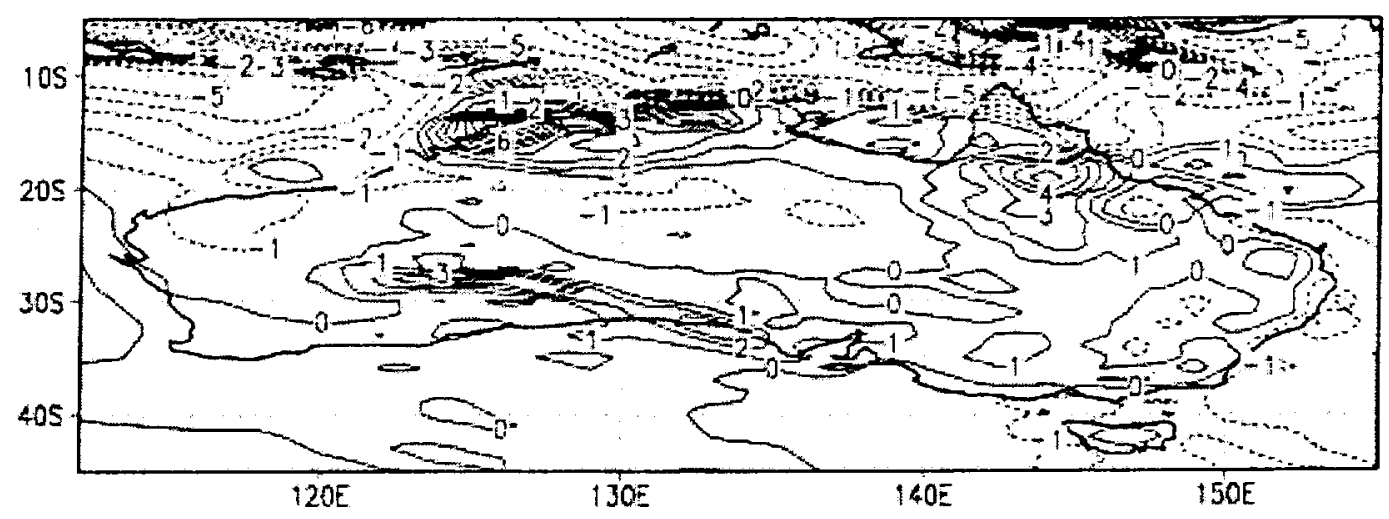

(c) XIE-ARKIN GAUGE ANOMALY DJ 1998 PRECIP

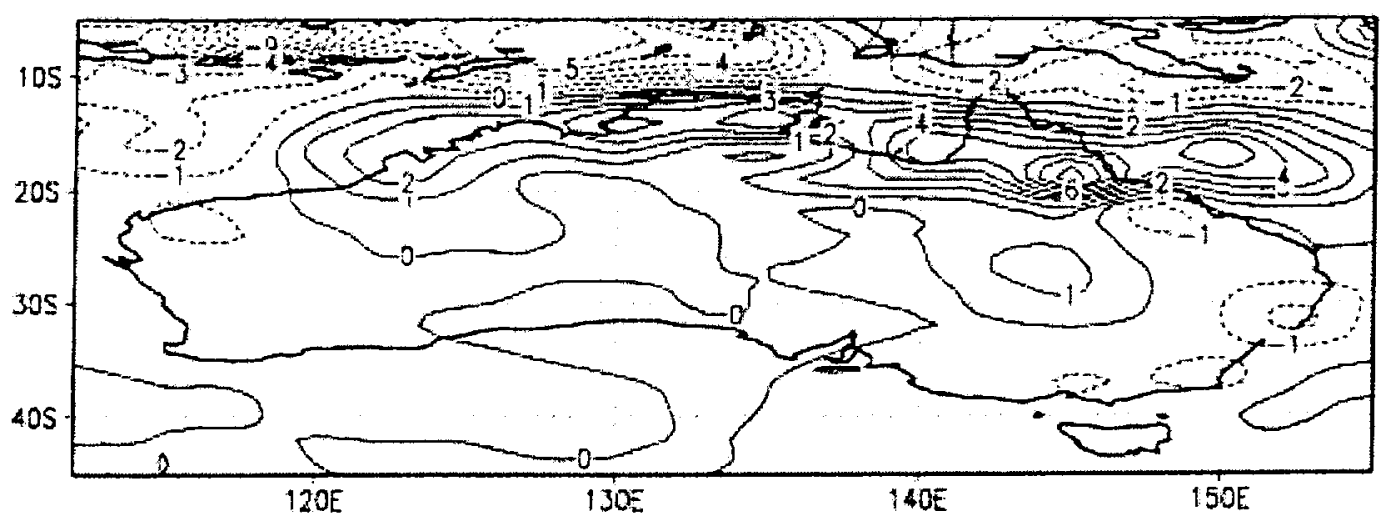

Fig. 15. The DJ (December 1997 and January 1998) precipitation anomalies over Australia for the: (a) SG-GCM, (b) SG-DAS, and (c) NCEP (Xie-Arkin) gauge data at 2 -degree resolution. The contour interval is $1 \mathrm{~mm} /$ day 


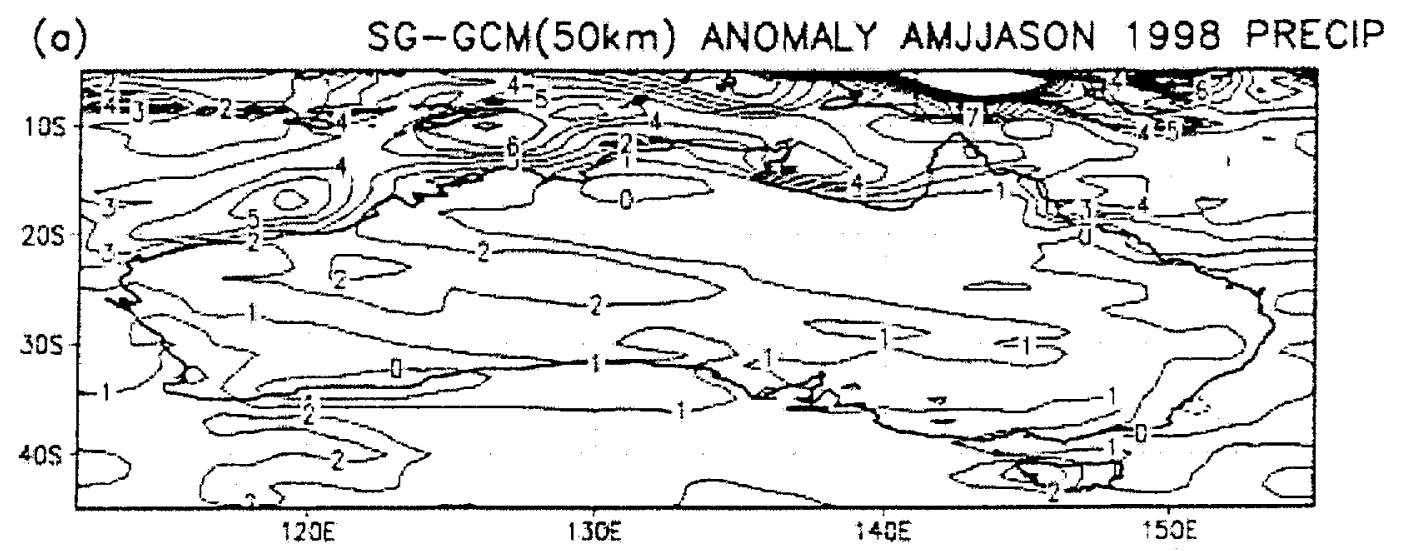

(b) SG-DAS(5OKM) ANOMALY AMJJASON 1998 PRECIP

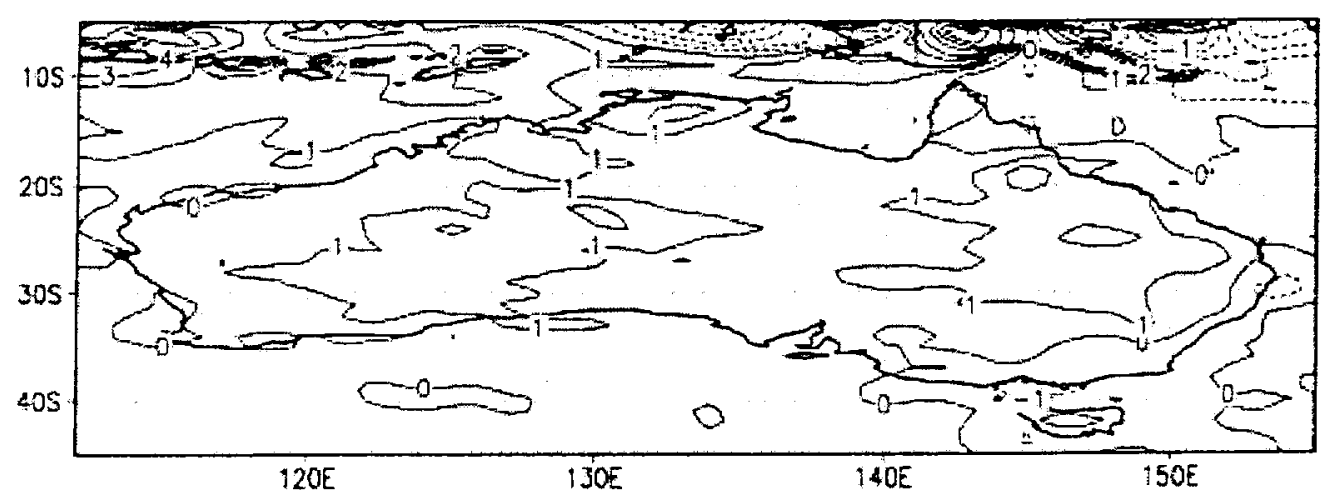

(c) XIE-ARKIN GAUGE ANOMALY AMJJASON 1998 PRECIP

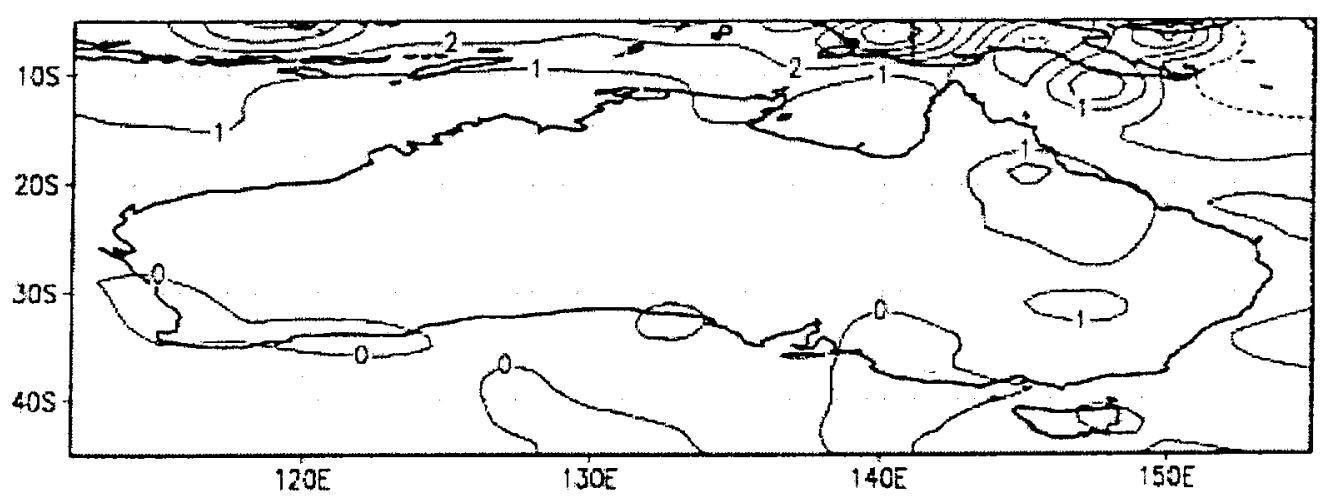

Fig. 16. The 1998 AMJJASON (April through November) precipitation anomalies over Australia for the: (a) SG-GCM, (b) SG-DAS, and (c) NCEP (Xie-Arkin) gauge data at 2-degree resolution. The contour interval is $1 \mathrm{~mm} /$ day. 


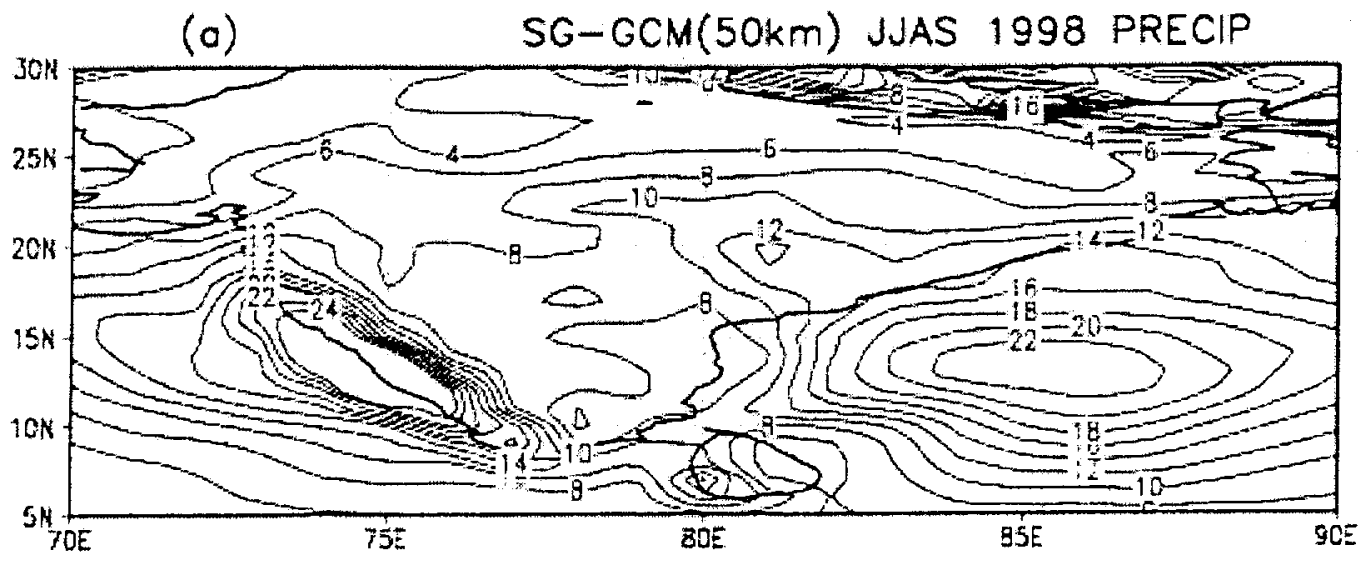

(b) SG-DAS(50KM) JJAS 1998 PRECIP

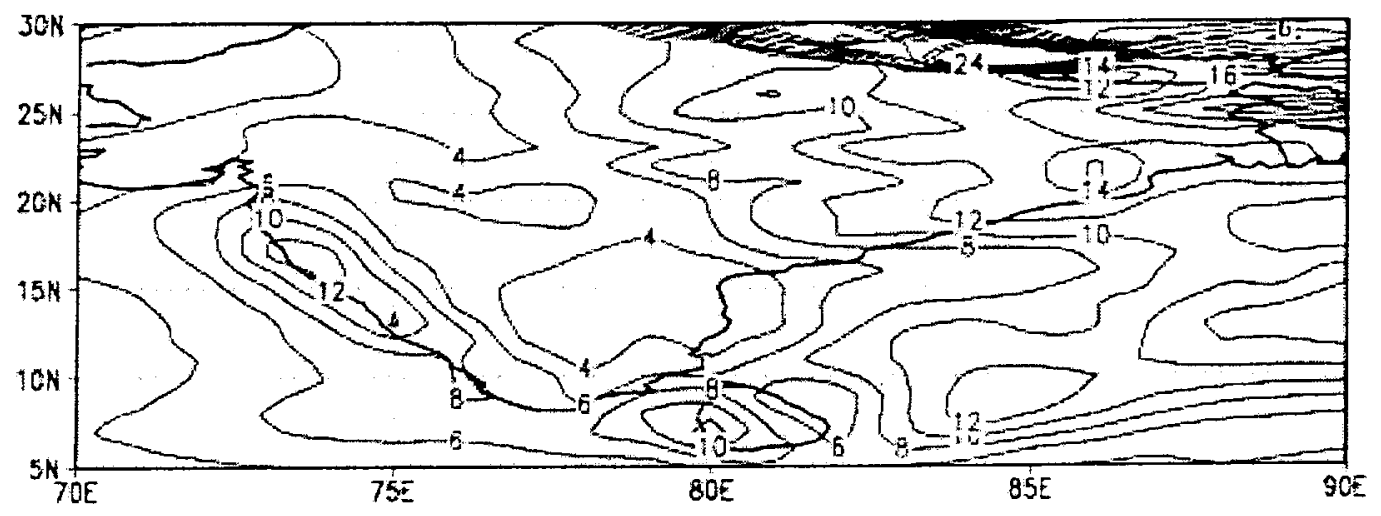

(c) XIE-ARKIN GAUGE JJAS 1998 PRECIP

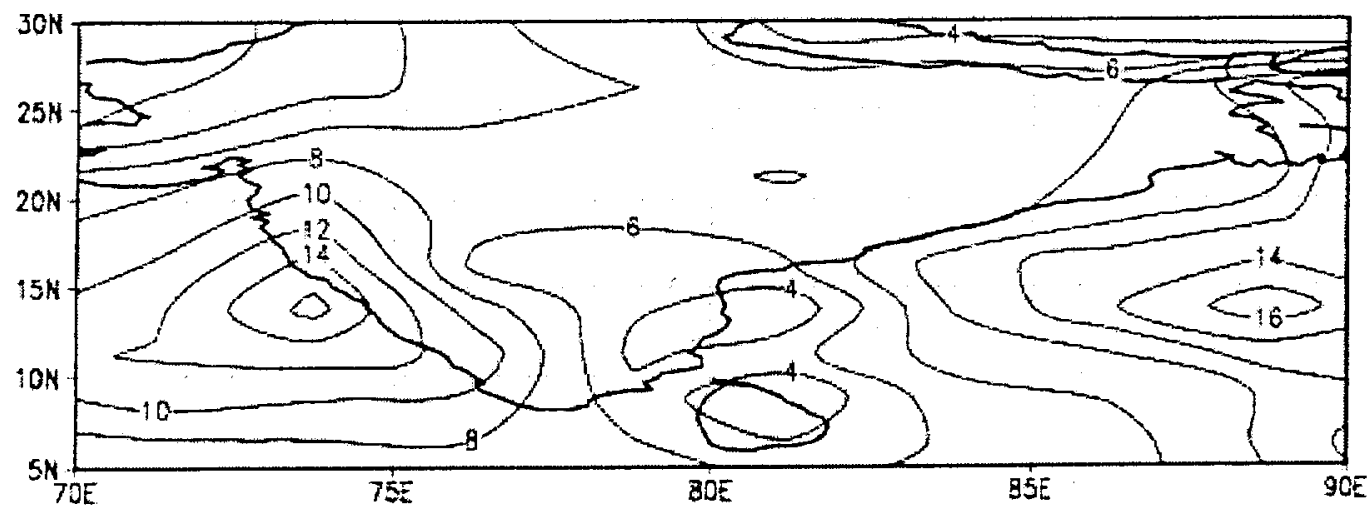

Fig. 17. The 1998 JJAS (June to September) precipitation over the Indian region for the: (a) SG-GCM, (b) SG-DAS, and (c) NCEP (Xie-Arkin) gauge data at 2-degree resolution. The contour interval is $2 \mathrm{~mm} /$ day. 
(a) SG-GCM(50km) JUAS 1998 PRECIP

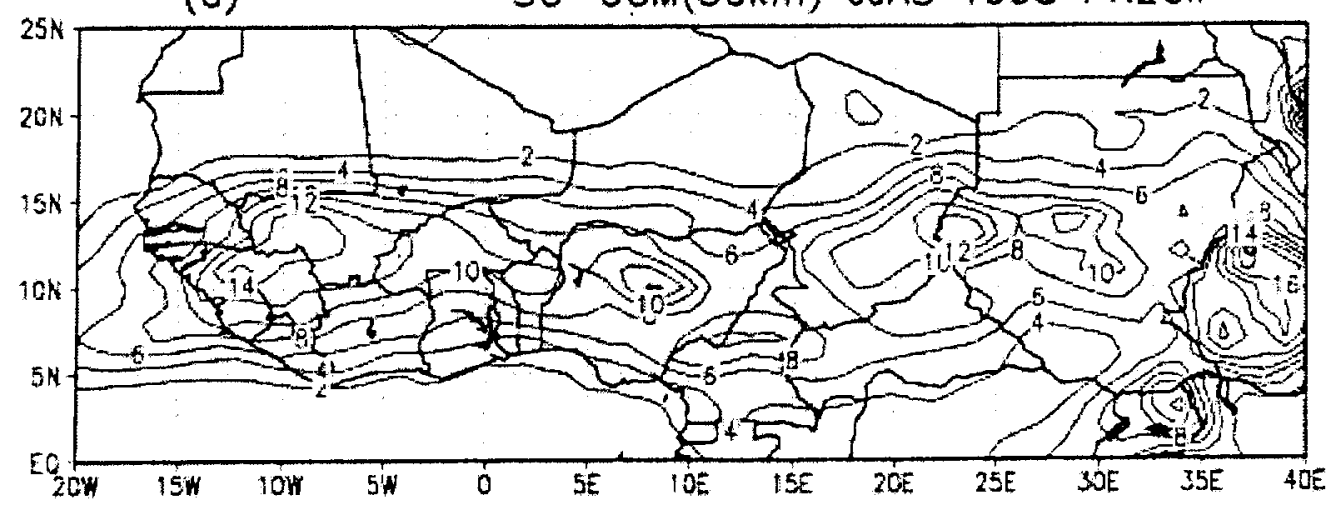

(b) SG-DAS(5OKM) JJAS 1998 PRECIP

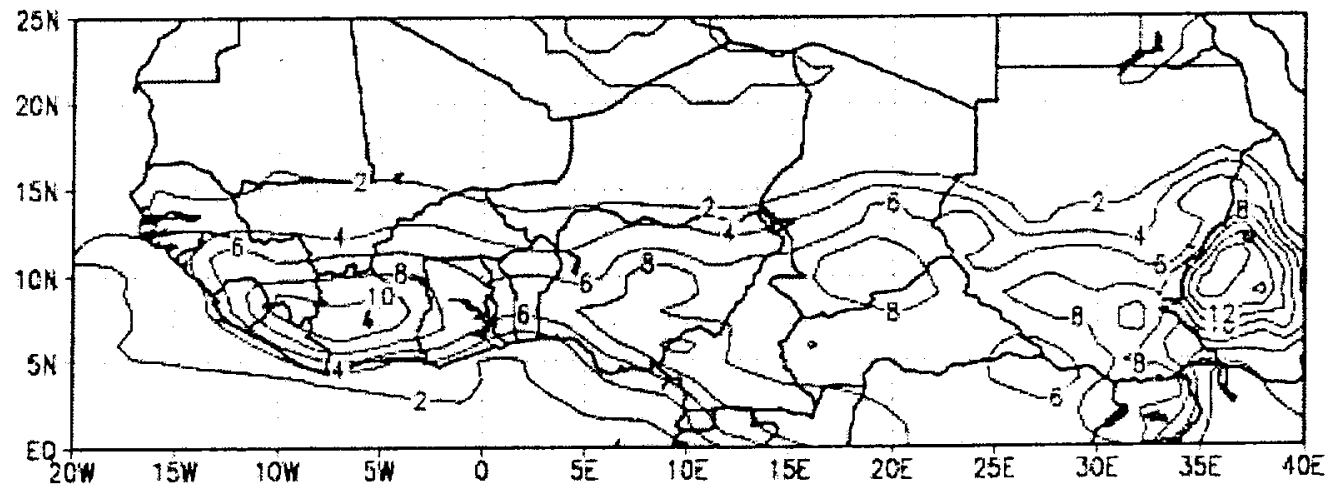

(c) XIE-ARKIN GAUGE JJAS 1998 PRECIP

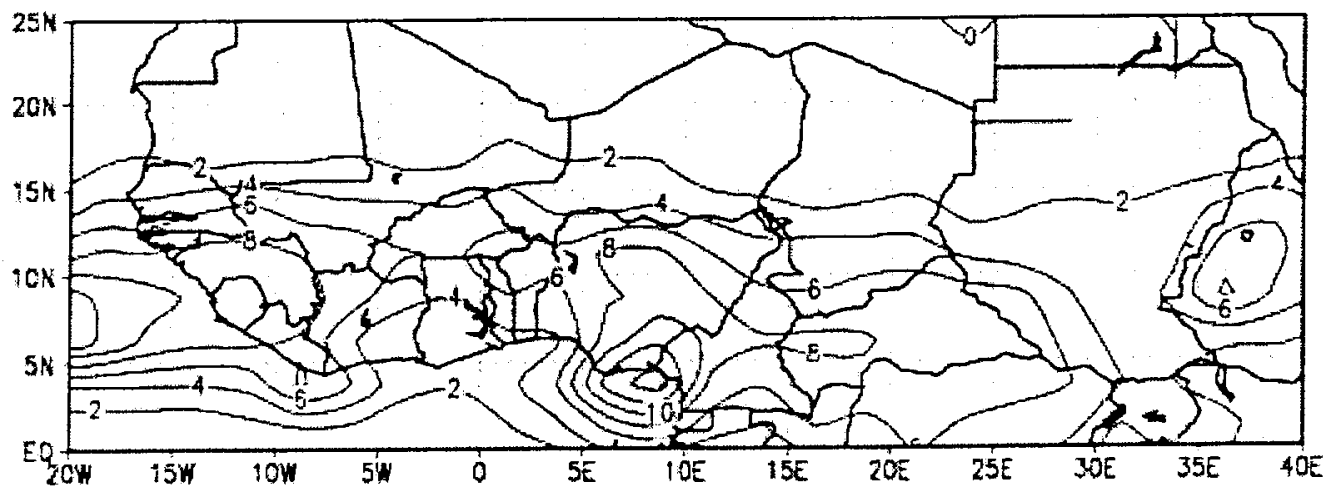

Fig. 18. The 1998 JJAS (June to September) precipitation over the African Sahel region and its vicinity for the: (a) SG-GCM, (b) SG-DAS, and (c) NCEP (Xie-Arkin) gauge data at 2-degree resolution. The contour interval is $2 \mathrm{~mm}$ /day. 
Popular summary:

\title{
A VARIABLE-RESOLUTION STRETCHED-GRID GENERAL CIRCULATION MODEL AND DATA ASSIMILATION SYSTEM WITH MULTIPLE AREAS OF INTEREST: \\ STUDYING THE ANOMALOUS REGIONAL CLIMATE EVENTS OF 1998
}

\author{
Michael S. Fox-Rabinovitz, ESSIC (Earth System Sciences \\ Interdisciplinary Center), University of Maryland, College Park, MD and \\ Data Assimilation Office, NASA/Goddard Space Flight Center, Greenbelt, \\ MD
}

Lawrence L. Takacs, and Ravi C. Govindaraju, SAIC (Science Applications International Corporation), 4600 Powder Mill Road, Beltsville, MD 20705-2675, and Data Assimilation Office, NASA/Goddard Space Flight Center, Greenbelt, MD

The new stretched-grid design with multiple (four) areas of interest, one at each global quadrant, is implemented into both a stretched-grid GCM and a stretched-grid data assimilation system (DAS). The four areas of interest include: the U.S./Northern Mexico, the El-Nino area/Central South America, India/China, and the Eastern Indian Ocean/Australia. Both the stretched-grid GCM and DAS annual (November 1997 through December 1998) integrations are performed with $50 \mathrm{~km}$ regional resolution. The efficient regional down-scaling to mesoscales is obtained for each of the four areas of interest while the consistent interactions between regional and global scales and the high quality of global circulation, are preserved. This is the advantage of the stretched-grid approach. 